\title{
Law's Looking Glass: Expert Identification Evidence Derived from Photographic and Video Images
}

\author{
Gary Edmond, ${ }^{*}$ Katherine Biber, ${ }^{* *}$ Richard Kemp ${ }^{\dagger}$ and Glenn Porter ${ }^{\ddagger}$
}

\begin{abstract}
This article offers a critical overview of expert identification evidence based on images. It reviews the Australian case law and then, in an interdisciplinary manner, endeavours to explain methodological, technical and theoretical problems with facial mapping evidence. It suggests that extant admissibility jurisprudence and traditional safeguards associated with expert opinion evidence and the adversarial trial might not adequately protect those accused of committing criminal acts when they are confronted with incriminating expert identification evidence.
\end{abstract}

\section{Introduction}

Photography was present at the birth of the forensic sciences. Nineteenth century police and pathologists used photographs to document crime scenes and preserve evidence (Beavan 2002; Baden \& Roach 2002). Its use by Alphonse Bertillon (1853-1914) as a system for recording anthropometric measurements, places it among the earliest of the modern identification technologies (see e.g. Cole 2001; Hutchings 2001). Photographic and video images continue to play important roles in criminal justice systems, particularly in the investigation and prosecution of crime. Indeed, in recent decades the forensic use of images has been proliferating. Yet, photographic and video evidence is fraught with dangers. Images do not speak for themselves: they require interpretation. Critical writings have cautioned us about using images to prove things (Sontag 1977; Barthes 1981; Sekula 1984; Solomon-Godeau 1991; Tagg 1988, 1992; Biber 2007; Mnookin 1998; Golan 2004a;

Faculty of Law, University of New South Wales. This research was partially supported by the Australian Research Council (DP0771770) and forms part of a larger collaborative project. A version of this article was presented to the College of Law, the Australian National University, 15 May 2008. Edmond is the lead author and the other authors appear in alphabetical order.

** Faculty of Law, University of Technology Sydney. A version of this article was presented at the Critical Criminology Conference, Faculty of Law, UNSW, 17 June 2008.

$\dagger$ Department of Psychology, UNSW. Kemp has acted as a defence expert in criminal cases. He has also been engaged by applicants whose immigration status was challenged on the basis of facial mapping evidence. This research was partially supported by the Australian Research Council (DP0881623 and LX0883067).

\$ School of Natural Sciences, University of Western Sydney. Porter is Head of Program for the Bachelor of Science (Forensic Science) degree at University of Western Sydney. He has conducted casework and research into the reliability of photographic evidence. He recently presented the plenary lecture, on a related topic, to the Australian Academy of Forensic Sciences, Sydney, 28 May 2008. 
Valverde 2006; Young 1996, 2005; Loftus 1976; Porter 2007). This article considers the emergence of new forms of expert identification evidence and, via reference to a range of methodological, technical and theoretical criticisms, illustrates some of the limitations with the prevailing investigative and jurisprudential approaches to the use of images as evidence.

In recent years, following a qualified prohibition on police identification evidence by the High Court in Smith $v$ The Queen, Australian police, prosecutors and judges have increasingly looked to experts to interpret incriminating photographs and videos. Expert identification evidence based on such images is often described as facial mapping. Initially, the expert witnesses engaged in the aftermath of Smith sought to provide positive identification evidence. They opined that the accused and a person appearing in security (or surveillance) images were one and the same. Eventually, exhibiting some concern about this expert identification evidence, appellate courts restricted its scope to opinions about similarities between an unknown offender and the accused.

This article is critical of recent trends in expert identification evidence based on images, some of the associated forensic practices and the evolving jurisprudence. For, as we intend to explain, much of the incriminating facial mapping evidence now routinely accepted in Australian courts is of unknown validity and reliability. It is, in consequence, our contention that empirical research is required to demonstrate the reliability of expert identification based on images and, in addition, that until such research is produced judges and others should be reconsidering the terms on which the criminal justice system engages with ostensibly incriminating images and related opinion evidence.

\section{Facial (and Body) Mapping: Definition of a Non 'Field'}

By way of background, it is necessary to say a few things about facial mapping. Though revealing, the lack of an accepted definition complicates this task. The phrase 'facial mapping' is used to cover a wide range of practices and techniques which are not standardised through teaching institutions, formal qualifications and regulatory bodies, and have not been evaluated through published experimental studies. Nevertheless, English courts have allowed facial mappers, and those using facial mapping techniques, to give opinion evidence about the identity of persons in images since the early 1990s. ${ }^{1}$ The emergence of expert identification evidence based on images in Australia is more recent and relatively independent of the developments in England. Much of what follows, however, applies to facial mapping evidence in Australia and England.

Based on an international survey of those giving expert identification evidence derived from images, Kemp and Coulson (2008a) have proposed the following description of the comparisons associated with facial mapping:

[The contents of] [t]wo or more photographic, video or other images are compared to determine whether they depict the same person, or a photographic, video or other image is compared to a 'live' (i.e. corporeal) target ... to determine whether the image is of the target individual. The process of comparison might involve taking measurements, noting characteristics, or other techniques, and might concentrate on the face alone or might include other parts of the body. ${ }^{2}$

1 The jurisprudence governing the admissibility of expert opinion in England is quite different. Key English 'facial mapping' decisions include: $R v$ Stockwell; $R v$ Clarke; $R v$ Hookway; Attorney General's Reference (No 2 of 2002); $R$ v Gray.

2 'Body mapping' involves applying similar techniques to the body shape, body features, and movement. Those who use body shape and movement for purposes of identification may attempt to apply quantitative measures 
Basically, there seem to be two ways to classify facial mapping evidence: one quantitative and the other qualitative. Generally, quantitative approaches rely on the measurement of key features of the face and body (often termed 'landmarks'), as well as the distances and angles between these features. Such methods are often described as photo-anthropometry or photogrammetry (see Figure 1). The other, more qualitative, approach is concerned with the presence or absence of characteristic features, degrees of similarity and proportionality. These approaches are often referred to as morphological analyses or comparisons (see Figure 2).

The following definitions were reproduced in $R v$ Tang at [18].

\section{Photo-anthropometry}

Photo-anthropometry is a technique that attempts to metrically compare the proportional relationships of one photo to another rather than determine absolute visual similarities, as is done in morphological comparisons. It involves the analysis of anthropometric landmarks, dimensions and angles [simply] to quantify facial characteristics and proportions from a photograph.

\section{Morphology analysis [facial and body mapping]}

The feature by feature approach to evaluating faces, heads and bodies. It involves the comparison of two images - one from the crime scene and one of the suspect. It involves subdividing the face, head and body into components to obtain a thorough qualitative analysis and to determine visual similarities or differences.

In practice, it is not uncommon for witnesses giving expert identification evidence to incorporate elements of both approaches, though morphological analysis has come to dominate the Australian forensic experience.

Overall, the facial mapping evidence received in Australian courts is produced using a variety of methods and tools. Australian courts have encountered photo-anthropometry, morphological analysis, the comparisons of faces and bodies (using video, photographs and enlarged photoboards), the overlaying of two similar size images (photographic superimposition), the rapid transition between two images (blink technique), the gradual transformation of one image into another (swipes), as well as photo and video enlargement, enhancement and manipulation (see Figure 3 ). ${ }^{3}$

It is important to emphasise that the techniques and tools associated with facial mapping are not standardised and not always consistently applied by individual practitioners. ${ }^{4}$ One of the most conspicuous features of facial mapping and related forms of expert identification

(e.g. anthropometric calculations around height or shoe size) and/or describe similarities and differences between body shapes (especially somatotype) and movement (e.g. right-handedness). Often the same expert will be engaged in, and allowed to testify about, face and body comparisons. With the necessary adaptations virtually all of the issues canvassed in this article are applicable to body mapping as well as face and body mapping. We tend to use the terms 'facial mapping' and 'expert identification evidence based on images' interchangeably even though the latter is more encompassing and not restricted to heads and faces.

3 The photograph superimposition technique bears some resemblance to the 'composite portraiture' technique devised by Francis Galton (1822-1911), the British eugenicist, whose photographic superimpositions purportedly enabled him to identify the essential characteristics of criminal and racial 'types'. See Galton 1883.

4 Not all of the individuals involved in expert identification from images would describe themselves as 'facial mappers' or their work as 'facial mapping'. Our primary concern, however, is with the validity and reliability of expert identification evidence rather than nomenclature, professional alignments, disciplinary hierarchies or the experience(s) of individual expert witnesses. 
evidence is the absence of accepted procedures and protocols. At the heart of our critique lies a concern about the unknown validity and unknown reliability of facial mapping and related approaches to identification. We use the term to conveniently capture a diverse range of forensic practices. It is not our intention to reify 'facial mapping' or suggest that it is an established or credible 'field of expertise'.

Figure 1: Photogrammetric points and comparison. Once the images are scaled and oriented, the analyst compares sizes, distances and the angles between features and/or landmarks. (Figures 1 and 2 are from actual New Zealand case files. Courtesy of Rod McCourt, Global Intelligence Solutions.)

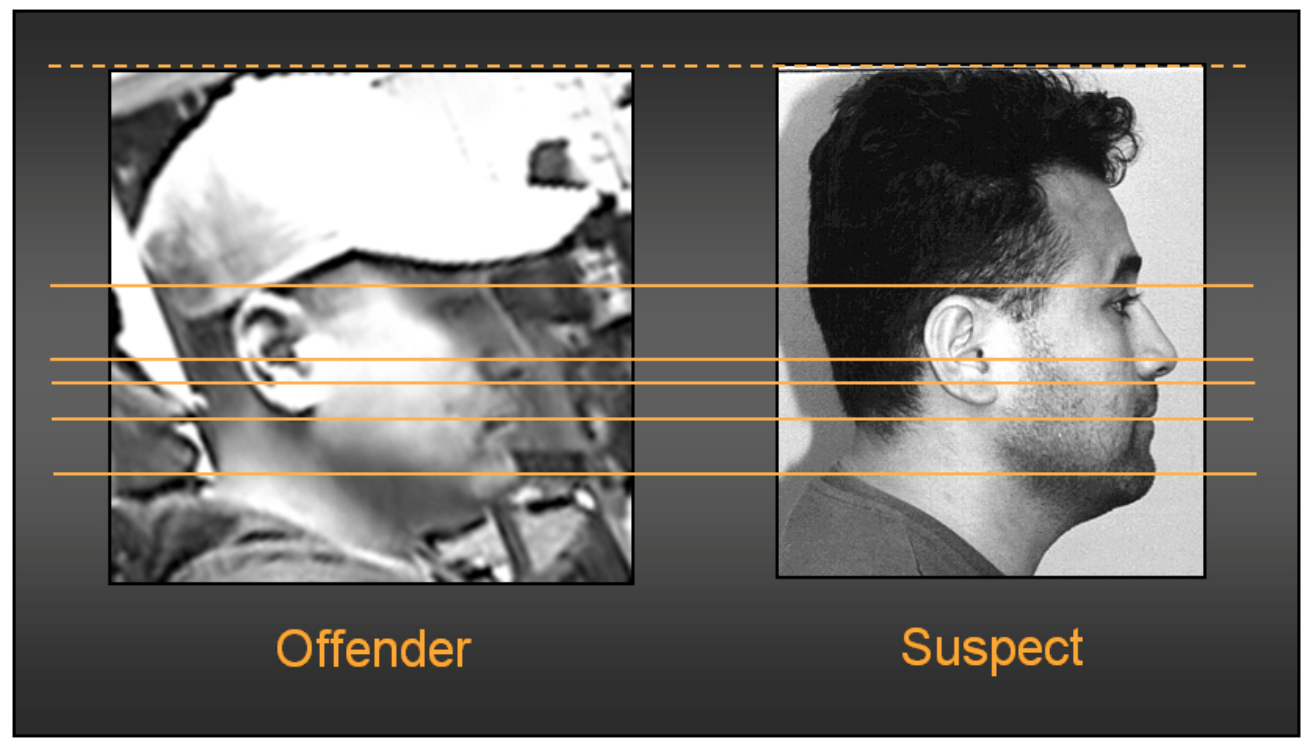

Figure 2: Morphological comparison of ears (from Figure 1). Morphological comparisons tend to focus on overall similarities as well as the degree of similarity between particular features such as ears, noses and lips.

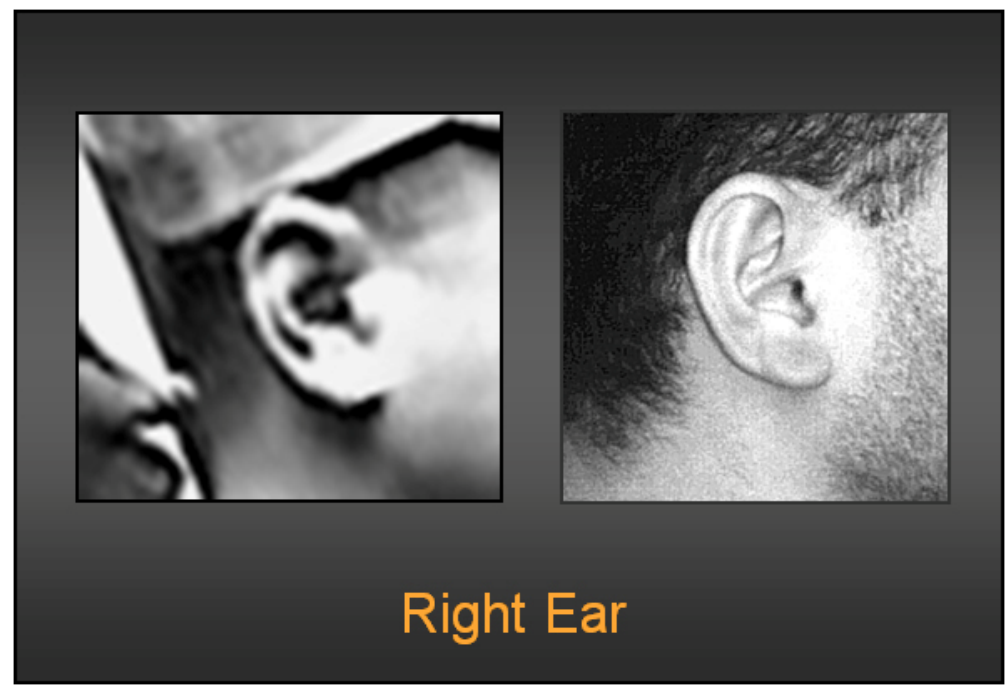


Figure 3: Photographic superimposition. Here, the face of Man B is superimposed onto the head of Man A (bottom left) and vice-versa (bottom right). (Once again these images are drawn from New Zealand case files. Courtesy of Rod McCourt, Global Intelligence Solutions.)

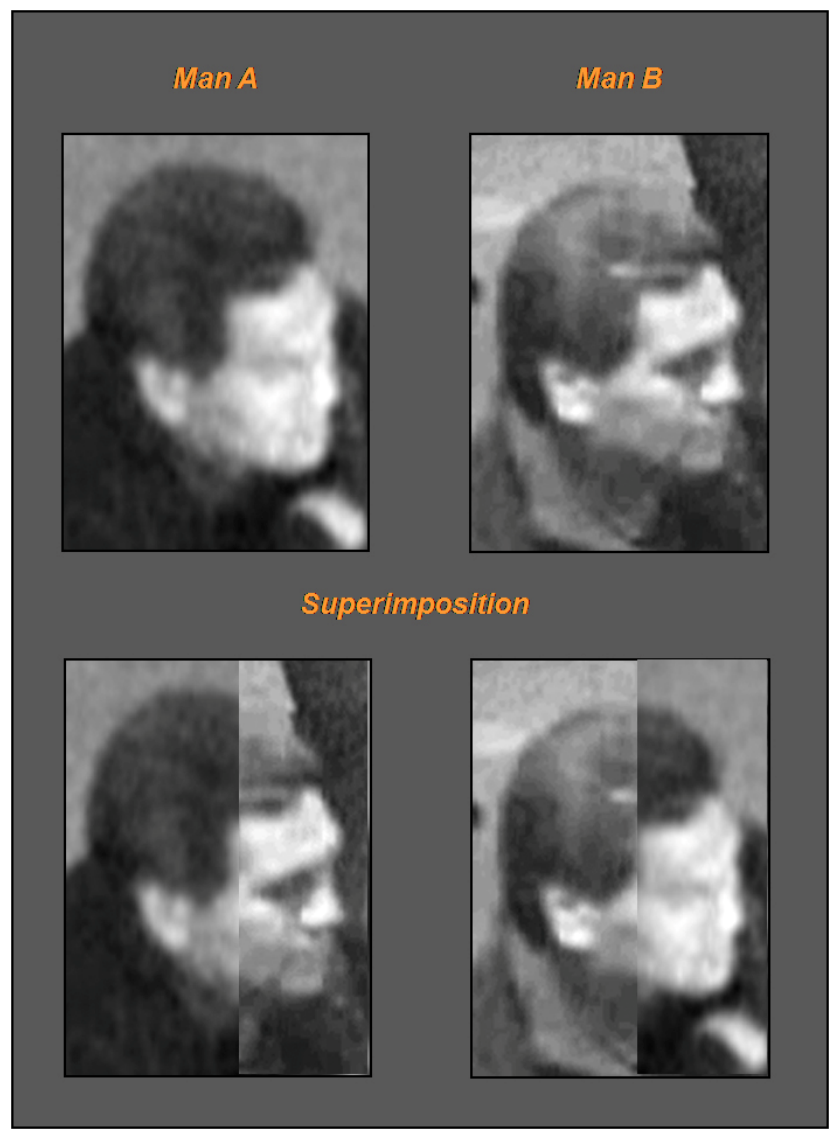

\section{The Emergence of Facial Mapping Evidence in Australia}

\section{A Brief Introduction to the Australian Admissibility Framework}

How is it that incriminating facial mapping evidence has gained access to Australian courts? To understand these developments we need to review the rules of admissibility prescribed by the Uniform Evidence Law (UEL). ${ }^{5}$

5 Most of the reported cases were tried and appealed in NSW. The Evidence Act 1995 (NSW) forms part of the UEL and is very similar to the Evidence Acts used in the ACT, Tasmania, the Federal Courts and Victoria in 
According to the UEL, to be admissible all evidence must be relevant:

\section{Relevant evidence to be admissible}

(1) Except as otherwise provided by this Act, evidence that is relevant in a proceeding is admissible in the proceeding.

(2) Evidence that is not relevant in the proceeding is not admissible.

Evidence is relevant if it has probative value. According to the UEL Dictionary the 'probative value of evidence means the extent to which the evidence could rationally affect the assessment of the probability of the existence of a fact in issue'. Consequently,

\section{Relevant evidence}

(1) The evidence that is relevant in a proceeding is evidence that, if it were accepted, could rationally affect (directly or indirectly) the assessment of the probability of the existence of a fact in issue in the proceeding. ...

Leaving aside the question of whether facial mapping evidence has probative value (more below), it has been admitted as a form of expert opinion evidence. Normally, even if relevant, opinions are presumptively inadmissible. The opinion rule (s76) states that 'evidence of an opinion' is not admissible 'to prove the existence of a fact about the existence of which the opinion was expressed'. There are, however, several exceptions to the exclusionary impact of the opinion rule. Although it does not attempt to codify the common law, s79 provides the major exception for expert opinion evidence. It reads:

\section{Exception: opinions based on specialised knowledge}

If a person has specialised knowledge based on the person's training, study or experience, the opinion rule does not apply to evidence of an opinion of that person that is wholly or substantially based on the knowledge.

Provided an 'opinion' is 'wholly or substantially' based on 'specialised knowledge' which is based on 'training, study or experience' it is not caught by the exclusionary opinion rule (see e.g. $H G v$ The Queen at [39]). Where these conditions are satisfied, a witness can proffer relevant opinions about facts in issue, subject to the exclusionary discretions. In criminal proceedings, incriminating evidence is to be excluded if its probative value is outweighed by the danger of unfair prejudice to the accused (s137). ${ }^{6}$ In all proceedings (i.e. civil and criminal), the probative value of the evidence may also be weighed against the danger that it is misleading, confusing, or an undue waste of time (ss 135 and 136).

At common law a witness is usually allowed to give expert opinion evidence if the opinion is legally relevant and they are an 'expert' in a recognisable 'field of knowledge' (Clark $v$ Ryan; Ramsay $v$ Watson; $R v$ Bonython at 46-47; for England, see $R v$ Robb). In addition, judges often considered, particularly in civil cases, the basis of the expert's opinion (Davie $v$ Edinburgh Magistrates). Interest in the reasoning behind the opinion has been carried over into the interpretation of s79 of the UEL (Makita (Australia) Pty Ltd $v$ Sprowles; ASIC v Rich at [249]-[259]).

the very near future. The following discussion, particularly the issues of validity, reliability and the exercise of judicial discretions, is also relevant to common law jurisdictions.

6 The judicial discretions based around weighing 'probative value' against 'unfair prejudice' are sometimes referred to as the Christie discretions after $R v$ Christie. 


\section{The High Court Creates a Need: Smith v The Queen (2001)}

The emergence in Australia of expert identification evidence based on images can be traced to the High Court's decision in Smith v The Queen (2001). ${ }^{7}$ Mundarra Smith was convicted for his participation in a bank robbery. The prosecution case relied upon the evidence of two police officers who testified that they knew Smith and recognised him from Closed Circuit Television (CCTV) images taken during the robbery (see Figure 4$).{ }^{8}$ The police officers testified at trial despite objection from Smith's counsel. In the NSW Court of Criminal Appeal (CCA) the admissibility of this evidence was challenged on the grounds that it was inadmissible opinion evidence ( $R v$ Smith 1999). The court considered the distinction between 'fact' and 'opinion' and concluded that the evidence of the police officers was evidence of fact - that is, recognition evidence - and not, therefore, caught by the exclusionary opinion rule. ${ }^{9}$

Figure 4: Security photograph from Smith $v$ The Queen. The person standing at the extreme right (with the dark hat) was identified by the police witnesses as Mundarra Smith. Reproduced with the permission of the District Court of NSW.

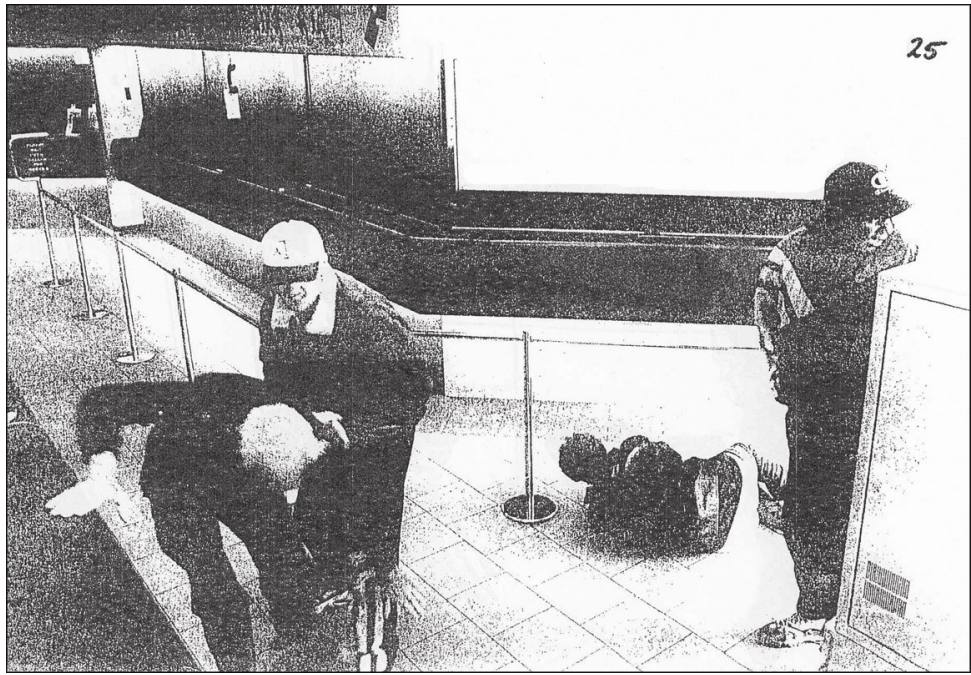

For further analysis of the Smith case, see Biber 2007 and 2006.

8 Here, we might note, that the police officers who purported to identify the offender in the image (as Smith) had each had about half a dozen encounters, including several 'brief (under five minute) conversations', with Smith in the months preceding the robbery. One of the officers had arrested Smith twice and estimated spending two to three hours with him each time.

9 Whether the evidence should be treated as 'fact', 'opinion' or 'recognition' evidence is, in actuality, quite a complex issue. Notably, this article does not concern itself with the opinions of witnesses who are very familiar with the person said to appear in images relevant to a crime. There are, however, good reasons to believe that lay people perform well when identifying individuals with whom they are very familiar even where the quality of the images is poor and the appearance brief. See, for example, $R v$ Marsh. There are undoubtedly dangers with lay identifications from images, but few prima facie reasons to prevent lay individuals giving their opinions about the identity of those with whom they are very familiar, especially where the images are clearly resolved and afford good opportunities to observe the face and/or movement. See Edmond \& San Roque 2009. 
On appeal to the High Court most of the judges adopted a different approach. There, for the first time, the issue of relevance emerged. The majority concluded that the evidence of the police officers was irrelevant and therefore inadmissible. The joint judgment explains the reasoning:

The police witnesses were in no better position to make a comparison between the appellant and the person in the photographs than the jurors or, for that matter, some members of the public who had been sitting in court observing the proceedings. ... Because the witness's assertion of identity was founded on material no different from the material available to the jury from its own observation, the witness's assertion that he recognised the appellant is not evidence that could rationally affect the assessment by the jury ... The fact that someone else has reached a conclusion about the identity of the accused and the person in the picture does not provide any logical basis for affecting the jury's assessment of the probability of the existence of that fact when the conclusion is based only on material that is not different in any substantial way from what is available to the jury (Smith $v$ The Queen 2001 at [11]). ${ }^{10}$

The majority, because they deemed the evidence of the police officers to have been irrelevant, did not broach the fact/opinion dichotomy.

Although he agreed that the evidence of the police officers was inadmissible, Justice Kirby did not consider their opinions to be irrelevant. He accepted that their evidence might have low probative value, but the UEL only requires that the evidence has the ability to 'rationally affect ... the assessment of the probability of the existence of a fact in issue'. For Kirby J, the opinions of the police officers could have, if accepted, 'rationally affected' such an assessment.

Having deemed the evidence relevant, Kirby $\mathrm{J}$ concluded there was no applicable exception to the opinion rule that would enable the police officers to testify about the identity of the offender. He explained:

Two possible bases for exception from the opinion rule were explored in argument. The exception for admitting evidence based on specialised knowledge provided by s 79 of the Act [UEL] can be disregarded, as no suggestion of such expertise was made in relation to the police officers. Their prior contact with the appellant did not amount to ad hoc expertise based on familiarity, nor did they claim any expertise in, for example, anatomical or photographic comparisons. The exception for lay opinion evidence provided by s 78 of the Act states:

The opinion rule does not apply to evidence of an opinion expressed by a person if:

(a) the opinion is based on what the person saw, heard or otherwise perceived about a matter or event, and

(b) evidence of the opinion is necessary to obtain an adequate account or understanding of the person's perception of the matter or event.

Neither police officer was present at the "matter or event" in question in the appellant's trial, namely the robbery. Although the security photographs record the robbery taking place, the opinion of the police officers is "based on" the photographs and not, as such, "based on" the robbery itself which they did not see, hear or otherwise perceive (Smith at [59]-[60] emphasis added).

10 This interpretation is controvertible as the police officers' exposure to Smith was purportedly independent and of a qualitatively different kind. They, for example, saw him moving, had interacted with him, and were often much closer than the jury. 
These judgments did not mean that police officers (and others) would be permanently prevented from testifying about the identity of persons in images associated with criminal acts. The majority described a range of circumstances where the evidence of police officers - whether construed as evidence of 'fact' or 'opinion' - might yet prove relevant and admissible.

In other cases, the evidence of identification will be relevant because it goes to an issue about the presence or absence of some identifying feature other than one apparent from observing the accused on trial and the photograph which is said to depict the accused. Thus, if it is suggested that the appearance of the accused, at trial, differs in some significant way from the accused's appearance at the time of the offence, evidence from someone who knew how the accused looked at the time of the offence, that the picture depicted the accused as he or she appeared at that time, would not be irrelevant. Or if it is suggested that there is some distinctive feature revealed by the photographs (as, for example, a manner of walking) which would not be apparent to the jury in court, evidence both of that fact and the witness's conclusion of identity would not be irrelevant (Smith at [15] emphasis added).

And, Kirby J adverted to the possibility of engaging the services of those with 'anatomical' or 'photographic' expertise.

Until Smith, police officers and other investigators routinely made positive identifications from images based on their prior interactions with the accused or the limited familiarity gained through the course of an investigation. After Smith, investigators and prosecutors effectively had two options. First, they could endeavour to utilise the exceptions to irrelevance identified by the majority in the extract above. These exceptions enabled investigators and police, in an ever-expanding range of circumstances, to proffer identification evidence linking a known individual to a suspect in a photograph or video associated with a criminal act. ${ }^{11}$ Second, police and prosecutors could seek the assistance of those with expertise - that is, pre-existing expertise - in disciplines such as anatomy, physical anthropology and photography. These experts, because of their 'specialised knowledge', would be able to give evidence about the identity of persons in images in a way that would provide an admissible exception to the rule against opinion evidence. It is this later form of opinion evidence that has given rise to facial mapping and its attendant dangers.

\section{Disciplining Professional Vision: From Positive Identifications to Similarities}

In the years immediately after Smith, expert identification evidence based on images seems to have received limited jurisprudential attention in Australian courts and tribunals. However, in the wake of the incident with the MV Tampa, tough scrutiny of asylum seekers spawned some of the earliest uses of facial mapping evidence in the context of immigration and border security (see also Marr 2003). ${ }^{12}$ In SHJB v Minister for Immigration and Multicultural and Indigenous Affairs, for example, the Minister relied upon the opinion evidence of a forensic anthropologist. There, Dr Watt testified that his morphological and

\footnotetext{
See, for example, $R v L i$ and the treatment of voice recordings in $L i$ and $R v$ Leung and Wong.

12 In 2001 a Norwegian registered ship, the MV Tampa, rescued 438 Afghans from a distressed fishing vessel in international waters off the Western Australian coast and sought passage to Christmas Island, an Australian territory. The conservative Australian Government refused the Tampa entry into Australian waters and deployed soldiers to assist that end. The action created a diplomatic incident between Australia, Norway, and Indonesia.
} 
anthropometric comparisons of passport photographs enabled him to identify an asylum seeker, purporting to be from Afghanistan, as a known Pakistani national. Both the Refugee Review Tribunal and Justice Selway in the Federal Court of Australia accepted this evidence. ${ }^{13}$ Shortly thereafter, expert identification evidence based on images began to appear more frequently in criminal proceedings.

Interestingly, facial mapping faltered at first in the criminal courts. The District Court of NSW became the first recorded Australian jurisdiction to take a critical stance against the admissibility of facial mapping evidence. In $R v B L M$, face and body mapping evidence was admitted in a trial at the Bidura Children's Court and used to link $M$ to an armed robbery. ${ }^{14}$ Dr Meiya Sutisno, described as 'a doctor of philosophy and medicine from the University of Sydney', used photo-anthropometry, morphology and photo superimposition to make a positive identification - that the accused and the offender 'were the same person' - based upon her examination of images recorded by a CCTV system (BLM at 3). ${ }^{15} \mathrm{Dr}$ Sutisno was, at that time, apparently unwilling to disclose her techniques, particularly the points she relied upon for facial comparisons and identification, because of concerns about her intellectual property rights. On appeal, Chief Judge Blanch expressed his unease at the reluctance of this witness to disclose or explain the techniques which supposedly enabled her to make a positive identification $(B L M$ at 4,10$)$. Without an understanding of the basis for her opinion, the tribunal of fact was in no position to assess Dr Sutisno's opinion evidence. Even though Blanch DCJ thought that some of the comparison evidence might be admissible, the magistrate's decision to admit Dr Sutisno's identification evidence was deemed to have been in error and the appeal was upheld.

These ignominious beginnings were but a temporary setback for facial mapping in Australian criminal courts.

Later in 2005, in the Supreme Court of the Northern Territory, Bradley John Murdoch was convicted of the murder of Peter Falconio and the abduction of Joanne Lees. During the trial, prosecutors adduced and relied upon Dr Sutisno's morphological assessment to implicate Murdoch $\left(R v\right.$ Murdoch at [82]). ${ }^{16}$ The circumstantial prosecution case included poorly resolved images of a person refuelling a vehicle, similar to one owned by Murdoch, in the relevant vicinity at a time proximate to the murder and abduction (see Figure 5). The images, described by the court as 'enhanced', were of such poor quality that the number plate, adjacent to where the person of interest was standing, could not be resolved (see Figure 5(b)) $(R v$ Murdoch at [3]-[55], especially [10], [11], [12], [18], [20]; apparently the digital images were converted to analogue and then re-digitised and enhanced).

Nevertheless, at trial Dr Sutisno was allowed to testify, based on comparisons of the video images taken at the truck stop and reference images of Murdoch, that in her opinion it was Murdoch at the truck stop. Chief Justice Martin made the following comments in his admissibility determination:

SHJB v Minister for Immigration and Multicultural and Indigenous Affairs (Kemp was called by lawyers for SHJB); NAFC v Minister for Immigration and Multicultural and Indigenous Affairs. See, more generally, Good 2006.

14 In the matter of the appeal of BLM (unreported) District Court of NSW, 14 September 2005.

15 Dr Sutisno holds a BSc (Hons) and a PhD in anatomy from the University of Sydney. Her PhD thesis is titled 'Human facial soft-tissue thickness and its value in forensic reconstruction' (2003), and is concerned with the identification of human remains. While many of the leading cases seem to involve Dr Sutisno there are other expert witnesses providing similar types of identification evidence.

16 Dr Sutisno was described by the court as a 'forensic anatomist' who had gained 'anthropological experience'. 
Dr Sutisno was an impressive witness. She is highly qualified and experienced in her field. ... Applying both morphological analysis and photographic superimposition, Dr Sutisno concluded that the person depicted in the image taken from the security film was the accused. She was unable to identify any differences of significance (Murdoch at [95] emphasis added).

The case of $B L M$ was distinguished because Martin CJ was satisfied that 'the principles underlying the work of Dr Sutisno can be readily understood' (Murdoch at [112]). ${ }^{17}$

Figure 5: (a) Individual identified as Murdoch entering truck stop; (b) Vehicle identified as Murdoch's 'truck' at the truck stop (see number plate); (c) Individual identified as Murdoch at the truck stop counter. (Courtesy of the Northern Territory Police.)
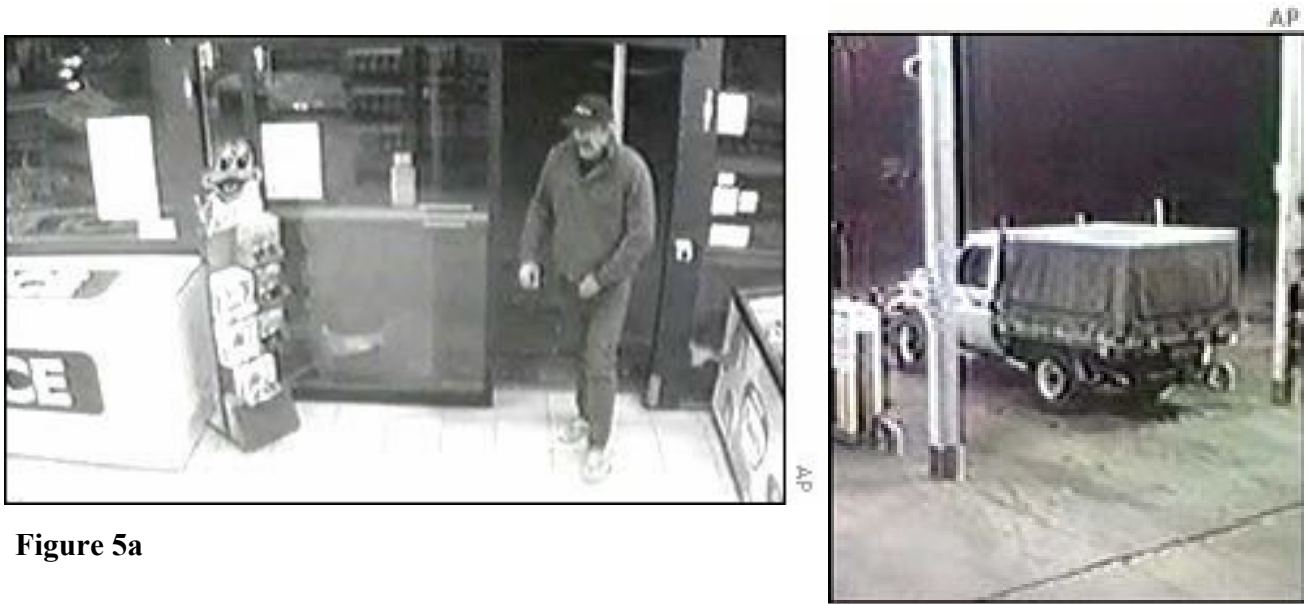

Figure 5a

Figure 5b

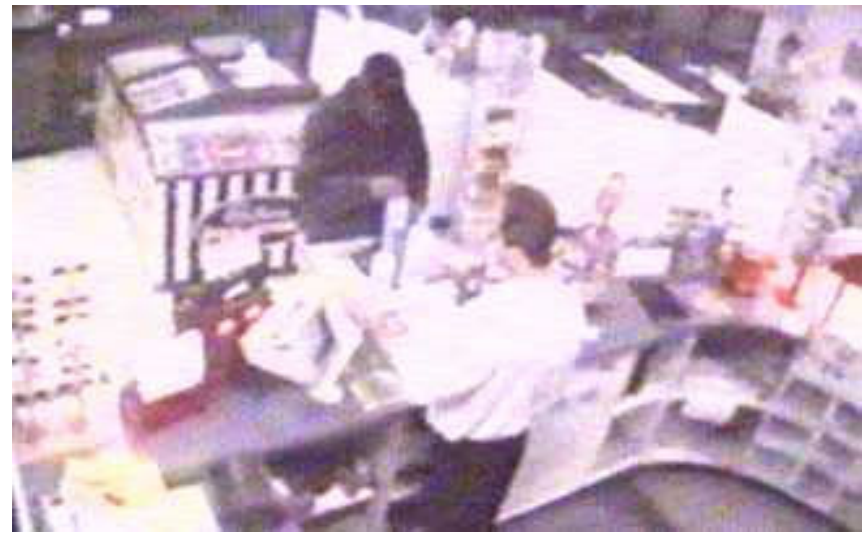

Figure 5c

17 In Murdoch, Dr Sutisno did not rely upon anthropometrical techniques and evidence. 
At about the same time the prosecution adduced and relied upon Dr Sutisno's facial mapping evidence in the Supreme Court of NSW. In $R v$ Tang positive identification evidence was admitted in a prosecution for armed robbery. Dr Sutisno testified that Hien Puoc Tang and a person in a series of incriminating images were 'one and the same' $(R v$ Tang at [23]-[28]). This was based on morphological comparison and the presence of what were described as 'unique identifiers' (Tang at [27], [18], [26]). ${ }^{18}$ Dr Sutisno concluded:

$[\mathrm{I}] \mathrm{t}$ is my opinion that the multiplicity of common morphological features, unique identifiers and Asian characteristics to (sic) lend support that the offender and alleged suspect Hien TANG are one and the same (Tang at [28] italics added).

During cross-examination Dr Sutisno rejected the suggestion 'that there was a degree of subjectivity in her assessment' (i.e., in her morphological comparisons; Tang at [78]-[81]).

The appeal in Tang provided an Australian appellate court with the first opportunity to consider facial mapping evidence. Writing for the Court of Criminal Appeal, Chief Justice Spigelman expressed doubts about the facial and body mapping evidence presented by $\mathrm{Dr}$ Sutisno. In his judgment facial mapping - 'let alone body mapping' - evidence did not constitute 'specialised knowledge' (s79) and was incapable of supporting expert opinion as to identity.

The evidence in this trial did not disclose, and did not permit a finding, that Dr Sutisno's evidence was based on a study of anatomy. That evidence barely, if at all, rose above a subjective belief and it did not, in my opinion, manifest anything of a "specialised" character. It was not, in my opinion, shown to be "specialised knowledge" within the meaning of s79 (Tang at [140]; though compare [135]).

And:

Facial mapping, let alone body mapping, was not shown, on the evidence in the trial, to constitute "specialised knowledge" of a character which can support an opinion of identity (Tang at [146]).

Curiously, rather than simply exclude the expert identification evidence, the Chief Justice accepted that Dr Sutisno's anatomical qualifications and experience enabled her to observe and describe similarities and differences between the person in the security images and the reference photographs of the accused. Her opinion evidence could be admitted as 'ad hoc expertise'.

The identification of points of similarity by Dr Sutisno was based on her skill and training, particularly with respect to facial anatomy. It was also based on her experience with conducting such comparisons on a number of other occasions. Indeed, it could be supported by the experience gained with respect to the videotape itself through the course of multiple viewing, detailed selection, identification and magnification of images. By this process she had become what is sometimes referred to as an "ad hoc expert" (Tang at [120] emphasis added). ${ }^{19}$

18 Interestingly, in practice, 'unique identifiers' were not quite as unique as might have been imagined. Rather than scars, marks and tattoos, features such as 'wide and thick upper and lower lips, wide square chin with dimple' and 'relatively upright posture', have been used as 'unique identifiers' that enabled Dr Sutisno to testify in the oxymoronic terminology of 'definitive resemblances'.

19 For criticism of ad hoc expertise, see Edmond \& San Roque 2009. 
For the CCA, Dr Sutisno's positive identification evidence was improperly admitted. Tang was entitled to a re-trial where Dr Sutisno, if called, would be restricted to describing similarities. $^{20}$

The evidence of Dr Sutisno of similarity, at least with respect to the facial features, is capable of adding strength to the Crown's circumstantial case. Even if she is not able to express the conclusory opinions of the character she did express, she can give evidence which supports of (sic) the Crown case (Tang at [157]).

Of significance, in its associated review of the admissibility of opinion evidence based on 'specialised knowledge' under s79 of the UEL, the Tang Court dismissed the need for reliability:

The focus of attention must be on the words "specialised knowledge", not on the introduction of an extraneous idea such as "reliability" (Tang at [137]). ${ }^{21}$

Here, in an appeal concerning the admissibility of incriminating opinion evidence, the validity and reliability of the evidence was regarded by the Chief Justice as 'extraneous'. Incriminating facial mapping evidence remains admissible in the absence of: 'specialised knowledge'; an accepted 'field' or discipline; validated techniques; peer review and publication; a known error rate; and information about the practitioner's proficiency. The fact that the expert opinion evidence was not demonstrably reliable - and 'did not permit a finding that ... [it] was based on a study of anatomy', or 'rose above a subjective belief' was not enough to warrant its exclusion under the opinion rule and its exceptions (ss 76 and 79) or the exclusionary discretions (ss 135 and 137).

Despite the critical remarks of the Chief Justice in Tang, Dr Sutisno and others continue to proffer expert identification evidence based on images in the NSW criminal courts. In a murder trial in the Supreme Court of NSW, just months after the appeal in Tang, Justice Hall admitted Dr Sutisno's facial mapping evidence about the identity of a person in an ATM photograph. Responding to a challenge to the admissibility of this evidence Hall J explained:

The evidence does establish that Dr. Sutisno does have specialised knowledge based on study and experience in relation to facial characteristics in the context of issues concerned with establishing identification both of deceased persons and otherwise. Such has become a recognised field for expert analysis, albeit of fairly recent origin. The opinion she has expressed as to similarities is an opinion within that field of specialised knowledge ( $R v$ Jung at [55] emphasis added). ${ }^{22}$

In $R v$ Jung Dr Sutisno was allowed to give facial mapping evidence but, following Tang, was prevented from making positive assertions about identity. Her written reports gave 'conclusory opinions' but her testimony was restricted to the terms preferred by the CCA in Tang (Jung at [9]). ${ }^{23}$ Perhaps unremarkably, Justice Hislop adopted a similar approach in $R$ $v$ Kaliyanda. ${ }^{24}$ Here, again, most of the emphasis seems to have been placed on Dr Sutisno's

20 At the re-trial facial mapping evidence was not relied upon and Tang was convicted.

21 This approach resonates with the untenable High Court decision of Commissioner for Government Transport $v$ Adamcik and the influential English appeal in Robb.

22 The words 'and otherwise' make Dr Sutisno's expertise expansive in ways that may not be clearly indexed to 'training, study or experience', nor validity and reliability.

23 During cross-examination on the voir dire, Dr Sutisno 'was not prepared to admit that she could make a mistake' using her techniques.

$24 \quad R v$ Kaliyanda (unreported interlocutory judgment) Supreme Court of NSW, 17 October 2006. 
qualifications, training and experience as an anatomist specialising in facial reconstruction, rather than the more fundamental question of the existence of 'specialised knowledge' and whether her techniques and opinions - or facial mapping more generally - were valid and reliable. None of the judges involved in Tang, Jung and Kaliyanda inquired whether Dr Sutisno could actually do what she claimed.

In the course of just a few months, and notwithstanding Spigelman CJ's muted incredulity in Tang, facial mapping became a legally recognised form of 'specialised knowledge'.

This trend was confirmed at the end of 2006 when Murdoch appealed his conviction to the Northern Territory Court of Criminal Appeal. Among the grounds of appeal was the admissibility of Dr Sutisno's facial mapping evidence. Employing common law criteria, that court basically embraced the approach to facial mapping evidence proposed by the NSWCCA in Tang.

This Court has found that the technique employed by Dr Sutisno did not have a sufficient basis to render the results arrived at by that means part of a field of knowledge which is a proper subject of expert evidence. However the evidence given by Dr Sutisno was capable of assisting the jury in terms of similarities between the person depicted in the truck stop footage and the appellant. It was evidence that related to, and was admissible as, demonstrating similarities but was not admissible as to positive identity. Dr Sutisno was not qualified to give evidence, as she did, based on "face and body mapping" as to whether the two men were, indeed, the same man. Her evidence in this regard should not have been received (Murdoch v The Queen at [300] emphasis added). ${ }^{25}$

The Northern Territory CCA concluded that while Dr Sutisno should not have been allowed to make positive identifications, the admission of her testimony did not warrant a re-trial. ${ }^{26}$

Smith effectively created a need for experts to assist the prosecution with incriminating interpretations of images. Since Tang (and Murdoch) experts have been prevented from making positive identifications. Now, as Jung, Kaliyanda, and a number of subsequent cases - such as $R v$ Alrekabi and $R v$ Pera in the District Court of NSW - attest, facial mapping testimony has become a legally recognised form of 'specialised knowledge' admissible in criminal proceedings. ${ }^{27}$ Police and prosecutors in NSW now routinely retain the services of experts, such as anatomists and physical anthropologists, to examine images and to testify about apparent similarities between suspects and images of persons of interest.

\section{Methodological and Technical Problems}

Having reviewed the ways in which facial mapping evidence is used, in this section we endeavour to explain why much of the expert identification evidence based on images may be unreliable and unfairly prejudicial.

\footnotetext{
25 The Northern Territory uses the common law rather than the UEL.

26 The prosecution also relied upon low copy number (LCN) DNA evidence in Murdoch. This, as appeals in the UK suggest, seems to have its own reliability problems. See $R v$ Hoey at [64]-[65]. For some discussion of the case and the use of CCTV images in the investigation see Gans 2007a and 2007b. 
The discussion is divided into three main strands:

(A) The lack of validation studies and the unknown reliability of facial mapping techniques;

(B) Reasons why facial mapping techniques may be unreliable or lead to erroneous conclusions (whether positive identifications or apparent similarities); and

(C) The impact of facial mapping evidence on fact finders (and courts of appeal).

This discussion does not, it should be stressed, exclude the possibility of future developments through improved technology and research into the validity and reliability of identification techniques.

\section{Evaluating the Reliability and Validity of Facial Mapping}

Notwithstanding its routine use in the criminal courts of Australia, New Zealand and England, there is, curiously enough, no empirical evidence supporting the validity or reliability of facial mapping techniques. ${ }^{28}$

The validity of a technique is the extent to which it does what it is claimed to do, while reliability is a measure of consistency or the extent to which the technique will produce the same results when repeatedly applied under varying conditions or by different operators. Reliability and validity are features of most scientific measurement systems. Because the validity and reliability of facial mapping have never been assessed we do not know whether the technique can be used to undertake accurate identifications, or the extent to which the conclusions reached using this technique will be consistent regardless of the operator, the methodology, the equipment, or the kinds of images.

The reliability of a measurement technique is one of the factors which determines its accuracy and the probability that its application will result in an error ('the error rate'). All measurement systems have some level of error associated with their use. This is acceptable provided the error rate and accuracy of the system are known and taken into account. The required level of accuracy of measurement, along with the tolerance for error, will depend upon the use to which the technique is being put.

Where, as in the case of facial mapping, we attempt to use a measurement technique to make a binary (yes/no) decision (e.g. positive identification), the situation becomes more complicated. There are in fact two measures of accuracy and two measures of error rate to consider. If the objective of facial mapping is to decide whether or not two images are of the same person, then there are four possible outcomes. If the images are of the same person, we can either:

(i) correctly decide that they are of the same person (a hit), or

(ii) incorrectly decide that they are of different people (a miss or false negative error).

If the images are of different people we can either:

28 Some expert witnesses suggest that convictions provide an empirical confirmation for their incriminating opinions. This is highly misleading. In most cases the facial mapping evidence is merely part, even if sometimes an important part, of the prosecution case. We, however, do not know what led the fact finder to decide. Most of the time we have no way of knowing whether they reached the correct decision or not. Conviction is not, in any simple sense, indicative of the validity or reliability of a technique, especially when evidence derived from that technique - even if unreliable - played a part in securing the conviction. 
(iii) wrongly conclude that they are of the same person (a false alarm or false positive error), or

(iv) correctly decide they are of different people (a correct rejection). ${ }^{29}$

These outcomes are not independent of one another. If, for example, an operator always concludes that two images are of the same person, regardless of the evidence, the operator will have a perfect hit rate (i.e. 100 per cent), but will make a false positive error whenever presented with images of different people. In order to measure the ability of the operator to actually determine whether or not the two images are of the same person we need to measure both the hit rate and the false positive rate and combine these using a statistical technique known as signal detection theory (Stanislaw \& Todorov 1999).

Generally, the reliability, hit rate, false alarm rate and hence the validity of a system can be determined through a validation study. In the case of facial mapping, a standard validation study would ask subjects to evaluate pairs of images which the person administering the test knew to be of either the same or different people. In this way we could compare conclusions against the right answer. No formal evaluation of facial mapping has ever been attempted and as such we have no way of knowing how well the operators perform or even whether the same operator would reach the same conclusion when evaluating the same pair of images on separate occasions or against different background information. ${ }^{30}$

\section{Reasons to Doubt the Validity and Reliability of Facial Mapping Evidence}

In this sub-section we consider several factors that cast doubt on the value of facial mapping evidence. This discussion places the failure to undertake validation studies in a more critical light.

\section{Photographic Considerations and Technical Problems}

Practically, expert identification based on images involves comparing a questioned image (or images) with reference images of the suspect. In other areas of forensic identification, where photographs are the principal source for comparisons - such as footwear impressions, fingerprints, tyre impressions and toolmarks - strict controls are placed on the photographic capture of the questioned evidence and the recording of the exemplar (or reference) images and samples. Controls include: (a) making sure the image has sufficient resolution to resolve individual characteristics; (b) making sure the image integrity does not present problems with image distortion; and (c) using quality lighting (and sometimes chemicals) to enhance

Images or evidence may also be inconclusive. There may be questions about whether such evidence has probative value. See, for example, $R v$ Dann.

30 It might be argued that requiring a validation study is setting the bar too high. For, other widely accepted forensic techniques, such as fingerprinting, have never been formally evaluated in this way. Fingerprinting, however, is subject to proficiency testing designed to establish the analyst's knowledge of the techniques and procedures that should apply, along with their ability to apply those techniques. Although proficiency testing does not tell us whether the technique is valid (and this includes identification based on latent fingerprints), it does indicate whether the individuals involved understand what they are required to do. (What they actually do is a separate question.) In the case of facial mapping, we do not know if the various procedures are valid or if the operators are doing similar things. (We will return to this point later.) It is also important to recognise that identification from latent fingerprints is currently confronting a raft of criticisms caused by the rise of DNA typing and the failure to credibly validate the various techniques and assumptions. See, for example, Cole 2001, 2004, 2006; Lynch 2004. 
the visualisation of marks. Such controls and standards are designed to ensure that questioned and exemplar images are suitable for forensic examination and comparison (see Horswell 2004; Bodziak 2000). They are standard for most forensic photography applications.

Quality assurance also requires images to be taken with lenses free from rectilinear distortion (i.e. macro lenses) and the positioning of the camera in a way that effectively eliminates perspective distortion (caused by the camera angle). Camera exposure, lens focus, lighting and contrast should all be considered when comparing images of sufficient resolution and quality. Images sourced from CCTV cameras, mobile phones, ATMs and so on, generally do not meet the standards required in other forms of forensic identification and comparison. This tends to make the comparative analysis of images taken by CCTV (and other) cameras highly problematic.

The compatibility of the questioned and exemplar images is of critical importance and should promote a 'like-for-like' type of comparison. ${ }^{31}$ This means that the exemplar (or reference) materials should replicate the image conditions used to capture the 'incriminating' images. Two primary parameters are fundamental to the comparison of images (especially where the resolution is poor, more below). First, camera angles should match. This parameter might be considered obvious, yet courts and expert witnesses have routinely trivialised it. In other forms of comparative analysis photographs - e.g. footwear impressions and fingerprints - the camera is positioned perpendicular to the object (at $90^{\circ}$ ) to reduce distortion caused by variation in angles. Ideally, facial identification images should be taken from directly in front of the subject (e.g. passport photographs). Other angles will produce (perspective) distortion which significantly affects the representation of shape and size. ${ }^{32}$ Images sourced from most CCTV cameras are not taken perpendicular to the subject. Matching camera angle from sourced CCTV images is important to provide the same level of distortion encountered in the questioned and exemplar photographs (consider Figures 1 and 3 ). ${ }^{33}$ Second, image perspectives must be the same (or very similar). ${ }^{34}$ Remarkably, this issue has been largely ignored in forensic contexts. Though, as we shall see, image perspective raises serious questions about the abilities of some witnesses, particularly anatomists and physical anthropologists (and police officers), to make accurate comparisons (whether anthropometric or morphological) by simply comparing images.

Image perspective is a phenomenon resulting from the transformation of threedimensional objects into two-dimensional images. Image perspective can compress or expand visual space and can also change the size relationship between objects represented within an image. The three experimental images in Figure 6 were taken at different ' $u$ ' or

31 Porter \& Doran (2000) proposed a conservative - indeed exclusionary oriented proposal -for high quality frontal photographs like those on identification documents (e.g. passports). It does not, however, address problems with the distribution of body features, poorly resolved images or the influence of experts.

32 Perspective distortion can be observed in photographs of tall buildings taken from the ground with the camera pointing vertically. The resulting photograph represents the shape of the building as a curved trapezoid. In the resulting photograph, the size of the top of the tall building is smaller than the base which produces a distortion of relative size and shape. The same condition can be observed with facial morphology when nonperpendicular angles are used.

33 Comparative analysis of images displaying perspective distortion is undesirable for forensic examinations. Differences of shape and size will occur across the photographic frame and the representation of facial morphology is significantly affected.

34 Image perspective is different to the perspective distortion caused by camera angle. It is an inherent condition regardless of camera angle. 
camera distances. That is, the same subject was photographed at different distances from the theoretical centre of the lens. ${ }^{35}$

Figure 6: Experimental images showing apparent changes in facial morphology using different image perspectives ((a), (b), (c), from left to right). Each image is subjected to roughly the same magnification. All components in the image (foam head, ear, nose and linear scales) are the same. Pins, which appear as black points, identify anatomical 'landmarks'. (Images by G Porter.)

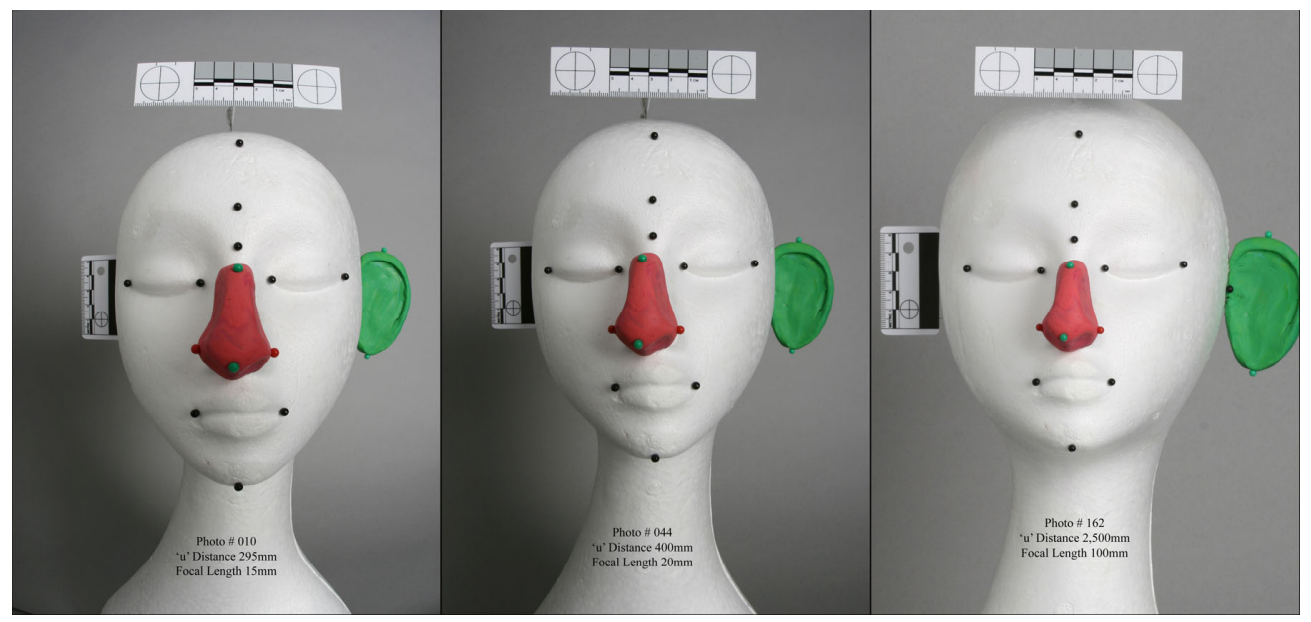

An examination of these three photographs reveals considerable differences in the representation of the facial morphology caused by image perspective. In particular:

- The nose appears to be shrinking in each photograph (from left to right), while the ear appears to be growing.

- There are significant differences in the relative sizes of ear and nose (morphological indices) in each of the photographs. The nose appears larger than the ear in the first photograph. They appear to be approximately the same size in the second photograph. The nose appears to be significantly smaller than the ear in the third photograph.

- The shape of the face, head and neck appear to be different in each of the images.

- The vertical height of the nose relative to the height of the ear appears to vary.

Similarly, any attempt to make an identification using anthropometry would have to overcome the effects of image perspective (and camera angles). The angles and distances between the landmark pins vary. Without more, re-orienting and re-scaling heads (and other

35 The ' $u$ ' distance is the physical distance between the theoretical centre of the lens (rear nodal point) and the subject. 
body parts) on computer screens and then measuring distances and angles between 'landmarks' is unlikely to produce useful, let alone reliable, information. ${ }^{36}$

The significant differences in facial morphology in Figure 6 illustrate the need to consider the consequences of image perspective when comparing images, particularly a small selection of still images taken from a longer CCTV recording. It suggests that the application of vague taxonomic descriptors, such as 'small', 'medium' and 'large', may be highly misleading in the context of expert identification evidence. Here, we might also note that the use of technical anatomical terminology to describe facial features and shapes does not overcome the more fundamental question of what the head, nose and ear actually look like in reality. Using taxonomic descriptions indicated by Allison (1973), the face represented in Figure 6 might be characterised as 'long' (a), 'oval' (b) and 'round' (c). Describing the shape of the face or using the relative size of facial features (e.g. ears and noses) or distance and angles between pins (i.e. landmarks) substitutes the appearance of an image for an undistorted reality. What, after all, is the actual shape of the head? In reflecting on such issues it is useful to remember that these are high-quality full-frontal parodies. Different camera angles and lower resolution would accentuate the difficulty and variability of any analysis.

Another common, and related, problem with images from CCTV cameras is the inability to record fine detail. This is commonly described as resolving power. Image resolution is often compromised in digital camera systems because of inexpensive optics and exacerbated by the compression and decompression algorithms used to store the large amounts of digital information (Porter 2008; Cohen et al 2007). CCTV systems are designed to display images on monitors. Obtaining still images for purposes of comparison is often problematic because of limitations with CCTV player software. Most software will capture still images from the footage, but frequently at a reduced resolution. This limits the ability to record or display the kinds of clearly resolved stills suited to comparative analysis.

Overall, parameters affecting resolution include:

- the resolution of the optical system;

- the degree of compression and decompression of the digital image;

- conversion of the images between digital and analogue and copying analogue images;

- the ability of the software to capture still images;

- the physical size of the digital image and extent of pixelation (also affected by increasing magnification);

- the range of the subject (e.g. the extent to which the face or feature fills the frame);

- the dynamic range of the image; and

- camera recording conditions, such as exposure, noise, lighting, cleanliness and the quality of lens.

Consequently, high resolution images are not always available.

36 Porter's research into the effects on facial morphology caused by image perspective suggests that morphological variations respond non-lineally. Signification variation occurs at distances between 0 and 1 metre, moderate variation between 1 and 3 metres and little variation occurs beyond 3 metres. 
Finally, it is desirable to address a popular misconception. Namely, that increasing image magnification (i.e. making the photographs or imaging larger in physical size) provides an increase of detail. Although true in principle, in practice it depends upon inherent qualities of the image. Magnification will increase the detail until the image quality parameters are exhausted. At this point any further increase will result in empty magnification. Empty magnification produces no increase of detail and in many cases the detail will be reduced. The parameters affecting empty magnification include: resolution, film grain or image noise, degree of subject movement, film format and digital image size (i.e. number of image pixels). The idea that magnification will simply and continuously increase detail is a gross simplification. The low resolution and image quality encountered in many contemporary CCTV systems affords little scope for magnification. Computer enhancement may help to obtain detail. However, enhancement is contingent upon properties of the recorded image. Figure 7 provides an example of the limits of magnification.

Figure 7: Example of empty magnification. Starting with a reasonably resolved image (A), the ear of the person of interest is magnified (through B-D). (Images by G Porter.)

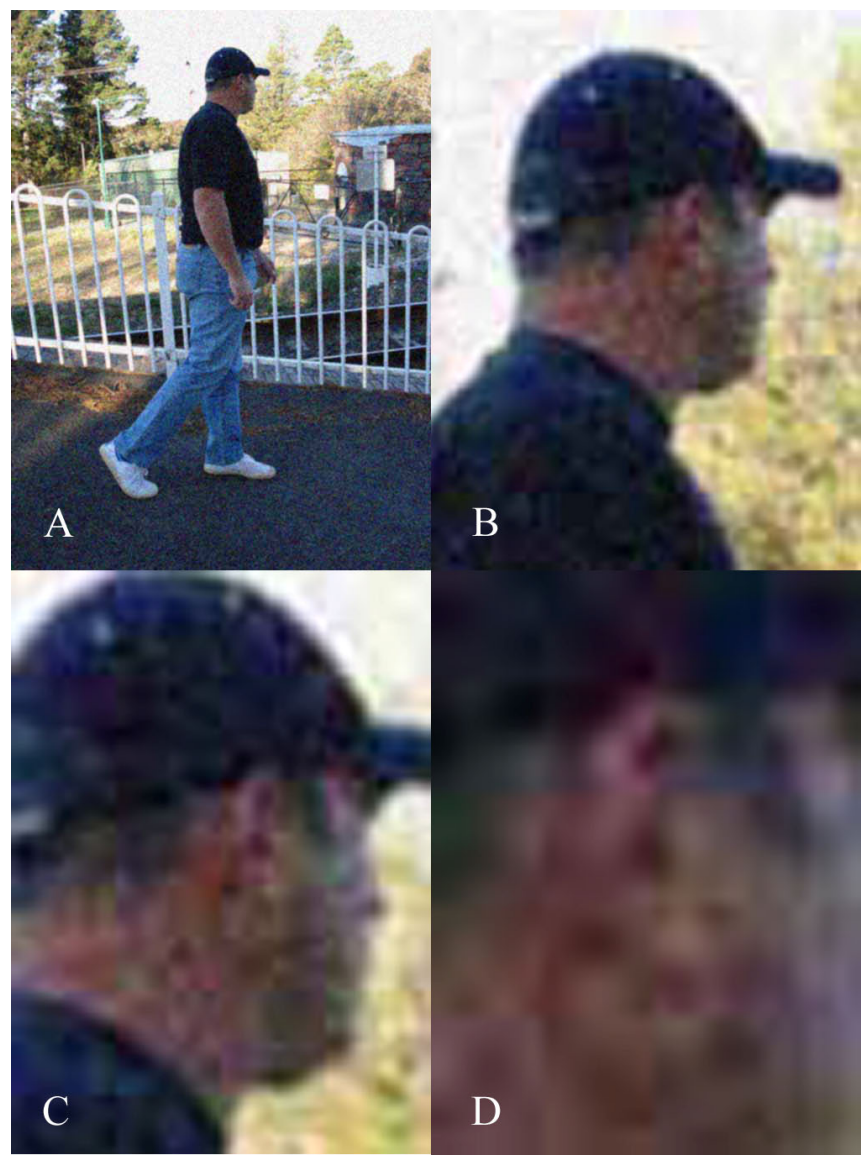




\section{Populations, Distributions and Statistical Issues}

Technical issues with images are compounded by the lack of information about the frequency and distribution of facial and body features and the relationships between features - particularly among population sub-groups.

To be reliable and accurate, identification based on images that is not predicated upon highly individualised features such as scars, 'blemishes' and tattoos, ought to rest upon detailed knowledge of the frequency of occurrence of various facial features within the relevant population. Without such data reliable conclusions can not be drawn from the observation that two images appear to share one or more characteristics. The observation that two images both display a particular facial characteristic, say a particular nose shape, only becomes probative if the image accurately captures the actual shape of the nose and we know how frequently that type of nose occurs within the relevant population.

Over the course of the last century anthropologists and others have measured relatively small groups of individuals, but we require far more detailed information to reliably estimate the frequency of the occurrence of one or more features. Mardia et al (1996:658) explain that:

The science behind this method, termed "facial mapping" by the UK press, is still emerging and the establishment of a reliable database of population statistics is now viewed as essential if we are to be able to lay down standards for facial comparisons which will ensure that any positive identification made is regarded as safe. ${ }^{37}$

Developing the requisite database would be a considerable undertaking. It would need to include accurate measurements of a large number of characteristics across many (perhaps thousands of) individuals, encompassing different ethnic groups and sub-groups, and also combinations derived from mixed or multiple ethnicities. ${ }^{38}$ It is not enough just to know how frequently a facial characteristic occurs within the relevant population; we would also require information about the statistical independence of features. ${ }^{39}$ If two or more features are correlated (i.e., if the occurrence of one feature predicts the occurrence of another feature) then the probability that two images share both these features is higher than if the features are statistically independent. In the extreme case where the correlation coefficient is 1.0 and the occurrence of the first feature perfectly predicts the occurrence of the second feature, then the observation that the two images share both features is no more informative that the observation that they share just one of these features. This can be easily explained.

Imagine that the individual depicted in a CCTV image has two distinctive facial characteristics. For example, he might be seen to have a particular shape of nose and a particular shape of ear (consider Purkait \& Singh 2008). If we had an adequate database, we might know that each of these characteristics is fairly rare, occurring in only 1 in 100 members of the relevant population. ${ }^{40}$ If these characteristics are statistically independent of

37 Consider also the US National Research Council (1996 and 2009).

38 This has raised problems for population statistics associated with DNA profiling. Consider Bropho $v$ Western Australia and Aronson 2007.

39 Most of the facial mapping decisions in Australia involve trials of persons of non-European origin.

40 Given the problems with image quality it may not always be possible to determine the relevant suspect population. Consider, for example, what does the head in Figure 6 actually look like? Could we confidently assign a population or sub-population group and if so on the basis of $4 \mathrm{a}, 4 \mathrm{~b}$ or $4 \mathrm{c}$ ? Here, it is important to 
each other, then the probability that someone selected at random from the relevant population will also have both of these characteristics is 0.0001 , or one in ten thousand (i.e. $0.01 \times 0.01=0.0001$ ), and on the face of it, this appears to provide strong support for the contention that the image is of the accused. However, if these characteristics are not independent of one another, for example if people with long noses also tend to have long ears, then it is much more likely that a person selected at random will have both these characteristics and the probative value of this evidence is greatly reduced (People $v$ Collins; Tribe 1971). The stronger the correlation between these two characteristics, the greater the likelihood a face will have both of these features. In their analysis of the faces of 358 young white males, Mardia et al (1996:673) observed correlations as high as 0.94 between certain pairs of facial measurements. Thus, to draw a meaningful conclusion from the observation that two images share a set of characteristics we need to know both the frequency of occurrence of each of these characteristics and the extent of the statistical correlation between each pair of features.

NSW courts have prevented facial mappers from presenting their conclusions in the form of probabilities (e.g. 'It is 95 per cent certain that these two images are of the same person'), requiring instead that expert witnesses describe the similarities they have observed between two images. ${ }^{41}$ Avoiding the use of probabilistic language does not, however, overcome the statistical problems described above. This change represents a switch from an explicit to an implicit probability. Indeed, changing the way conclusions are expressed may actually disguise faulty reasoning and the absence of underlying population information.

\section{The Absence of a Standardised Procedure}

Not only is there no validation and few credible attempts to overcome technical problems with images, but among facial mappers there is little evidence of standardisation.

Kemp and Coulson (2008a) undertook an international survey of all individuals involved in providing expert identification evidence from the examination of images. A total of 26 individuals from several countries responded to a series of questions about their background and training, the techniques they employ, and factors affecting the accuracy of their conclusions. The most striking finding was the diversity of the responses. A few respondents reported that they always obtained comparison images from the same location as the original surveillance image, thereby introducing the potential to address some of the problems created by angles and image perspective. Most, however, reported that they never did this. About one third of the respondents claimed to use published population data to compute the probability that the two images were of the same person. Other respondents indicated that there was no publicly available data capable of supporting such an approach. While some respondents reported that their technique was largely unaffected by differences in the angle of view, image quality or the elapsed time between two images, others reported that each of these factors would, to varying degrees, affect the accuracy of their results (though in ways that were not explained or quantified).

emphasise that it is accepted in DNA cases that it is appropriate to use the database linked to the relevant suspect. See, for example, $R v$ Pantoja; $R v$ Doheny and Adams.

41 This occurred in Alrekabi. Though not based on any studies, recourse to '95' was clearly an appeal to statistical significance and the trappings of experimental science. 


\section{Unconscious Influence}

These problems with expert identification are exacerbated by the inability of expert witnesses to overcome prejudicial biases. Several decades of experimental research demonstrate that an individual's expectations and prior beliefs tend to influence their judgment. Significantly, these findings apply to experts. One recent study illustrates how trained forensic scientists were not able to overcome biasing information even where that information is unrelated to their actual analysis.

Dror et al demonstrated that the conclusions reached by professional fingerprint examiners could be significantly influenced by extraneous information (Dror et al 2006; Dror \& Rosenthal 2008). In their study, five highly experienced fingerprint examiners were each re-presented with a pair of prints which, five years earlier, they had declared to be a match. The experts were unaware that they were considering samples they had previously matched, and on re-presentation the prints were accompanied by extraneous contextual information about the case which suggested that they did not match. Of the five experts tested, only one resisted the influence of the extraneous information and did not change their original opinion. Of the four others, three reversed their original decision and concluded that the prints did not match, while the fourth declared that it was not possible to make a definite determination. This experiment indicates that even highly trained individuals using standardised techniques can be influenced by expectations induced through contextual information.

In the case of facial mapping there are several significant biasing factors that probably influence the expert witness' opinion. For example, if the operator examines the surveillance image and the reference image simultaneously, there is a danger that ambiguous characteristics of the surveillance image will be resolved - in their judgment - by characteristics of the reference image. There is also the danger of suggestion, where the operator knows that others - typically investigating police - already believe that the two images are a match. Currently, it is standard procedure for investigating officers, in their communications with facial mappers, to disclose this information, and include the incriminating images and reference photographs within the same package. In Australia, it is exceptional for the police to include more than one set of reference photographs. Even when not formally disclosed, the suspicions of investigating officers tend to be unambiguous.

The UK barrister, Andrew Campbell-Tiech QC (2005), provides another example of the influence of exogenous factors. In this case four independent facial mapping analysts were asked to provide reports comparing surveillance images to reference images of a suspect in a murder investigation. Initially, all the analysts agreed there was some support for a match. ${ }^{42}$ Some time later, however, investigating police decided they had arrested the wrong person and identified a new suspect. The same analysts were then asked to compare the original CCTV images with photographs of the new suspect. This time two of the experts returned an 'inconclusive' finding, the third concluded that there was 'support' for the proposition that the images were not of the same person, and the fourth that there was 'powerful support' that they were the same person. ${ }^{43}$ The police then asked the third expert to reconsider his analysis, making it clear that they felt his most recent conclusion might be mistaken. On reviewing his findings, and without access to additional photographic

42 In England expert witnesses are permitted to give positive identification evidence. That is, they are allowed to say that the person in the suspect image is the person on trial. See Attorney General's Reference (No 2).

43 This pervasive terminology comes from Bromby 2003. 
evidence, the expert concluded that he could not exclude the possibility that the suspect was the person shown in the CCTV images. ${ }^{44}$

\section{The Influence of Expert Identification Evidence upon Jurors (and Others)}

In the previous sub-sections we explained that facial mapping techniques have not been formally evaluated, and identified a range of factors that tend to undermine the reliability of facial mapping evidence. This final sub-section compounds these other issues by suggesting that expert identification evidence is likely to exert considerable influence on the tribunal of fact.

Experimental research has demonstrated that, although we are able to recognise very familiar faces from poor quality images, we struggle to identify unfamiliar faces even when image quality (or resolution) is high. Kemp et al (1997) investigated the ability of shop assistants to determine whether a photograph on a credit card was of the unfamiliar person attempting to use the credit card to purchase goods. Although this task did not require the participants to remember the faces, overall performance was less than 50 per cent accurate. Burton et al (1999) showed students images from a CCTV system which monitored the entrance of a university building. Despite very poor image quality students were able to recognise academics who had taught them, but were unable to match high quality images of unfamiliar academics. Overall, these and other studies suggest that people make many errors when trying to determine whether two different images are of the same unfamiliar person. This, of course, is the task facing jurors when presented with surveillance images and a defendant in the dock (as in Smith).

In a recent experimental study of the influence of facial mapping evidence, Kemp et al (2008b) provided participants (undergraduate students) with high quality video sequences of a defendant in court. The participants were then shown CCTV sequences featuring either the defendant or a different individual fleeing a crime scene. Participants were required to decide whether the person in the CCTV material was the defendant. As part of the experiment they were also presented with expert opinion evidence led by either a hypothetical prosecution or defence. The results showed that the participants' initial judgments were often inaccurate. About half of the participants who saw someone other than the defendant were prepared to convict the defendant. However, once a participant had read an expert report, their verdict was predicted only by the content of the report. That is, most of the participants were persuaded to adopt the position advocated by the facial mapping expert even when that assessment was wrong.

In summary, it seems that jurors are likely to make identification errors based upon photographic and video evidence and to place considerable weight upon the opinions of expert witnesses even when they are wrong.

\section{Forensic Problems Caused by Expert Identification Evidence}

Having just explored some of the reasons why expert identification evidence based on images may be unreliable this section suggests that many of the traditional safeguards (e.g. admissibility standards, exclusionary discretions, cross-examination and judicial directions)

44 Here, it is useful to consider recent criticism of the language used by forensic pathologists and scientists in Canada. See Goudge 2008:44-45. 
may not be particularly effective means for identifying, exploring or managing evidentiary problems. Traditional adversarial procedures do not ensure that fact finders will be consistently or meaningfully exposed to methodological frailties or appreciate the extent to which expert opinions are based on appeals to experience and subjective assessments. ${ }^{45}$ The upshot, we contend, is that many of the limitations with expert identifications are not adequately conveyed and, in consequence, the protections afforded to the accused have primarily symbolic value.

\section{Admissibility Standards and Discretionary Exclusions}

Our existing admissibility standards and exclusionary discretions have done little to identify or alleviate the many problems with expert identification evidence based on images. ${ }^{46}$ The common law, with its emphasis on the existence of a 'field' and whether a person is an 'expert' (in that field), like the current approach to 'specialised knowledge' and the 'basis' of opinions under s79 of the UEL, have not encouraged judges to attend to the validity and reliability of expert opinion evidence. Instead, judges (and many lawyers) have focused attention on non-technical dimensions of expert identification evidence, such as formal qualifications and 'experience' - whether the witness has previously testified, and whether similar evidence has been received in other Anglophone jurisdictions. Unfortunately, formal qualifications, prior experience as an expert witness, and the practices in English courts tell us little about the validity or reliability of an expert's opinions.

Here it is useful to reiterate that there is no facial mapping 'field' or discipline, no specialised facial mapping knowledge, no university courses, no qualifications, no dedicated journals or textbooks, no attempts to standardise or regulate techniques, and no serious attempt to test or validate the range of methods used by its disparate practitioners. ${ }^{47}$ Almost all of the extant studies with relevance to identification from images are critical of facial mapping or suggest that identifications based on images require cautious empirically predicated responses. Most suggest that things are far more complicated than those proffering their opinion for the prosecution would seem - on the basis of their testimony and reports - to acknowledge (Costigan 2007; US National Research Council 2009). ${ }^{48}$

To the extent that judges have allowed anatomists and physical anthropologists (and even police officers as ad hoc experts) to testify we can only wonder what the 'basis' in their 'training, study and experience' actually is. How do these witnesses overcome the distortion caused by lenses and lighting? What in their training renders them proficient at making comparisons between two-dimensional images; especially where the images are of poor quality, taken from different angles, with different cameras, with different image perspectives, with months or years intervening? What relevance does facial reconstruction or anatomical terminology (or experience as a police officer) have to photographic

45 These have been described pejoratively as ipse dixit - 'dogmatic statement resting merely on the speaker's authority' - in some of the leading US and Australian decisions. See, for example, General Electric Co $v$ Joiner at 146 and Tang at [138].

46 Many of the issues canvassed here, for example, have not been raised or developed in trials and appeals. For a more expansive discussion of admissibility rules and discretions, see Edmond 2008b.

47 Consider the very loose framework described in the Association of Chief Police Officers of England, Wales and Northern Ireland, National working practices in facial imaging (2003). It is not our intention to suggest that university courses, standardisation and protocols could somehow overcome the failure to rigorously validate facial mapping techniques, but rather that these omissions and inadequacies exemplify the extent of the problems.

48 For an example of limitations working in very favourable experimental conditions, see Lynnerup et al 2003. 
comparisons and identifications ${ }^{49}$ Abilities, we contend, should be demonstrated rather than asserted, particularly where techniques and methods have obvious limitations, have been subjected to serious and unanswered criticism, and are susceptible to testing and validation.

In the wake of Makita (Australia) Pty Ltd v Sprowles (2001) lawyers and judges were encouraged to take a renewed interest in the basis of opinions derived using 'specialised knowledge':

[I]t must be established that the facts on which the opinion is based form a proper foundation for it; and the opinion of an expert requires demonstration or examination of the scientific or other intellectual basis of the conclusions reached: that is, the expert's evidence must explain how the field of "specialised knowledge" in which the witness is expert by reason of "training, study or experience", and on which the opinion is "wholly or substantially based", applies to the facts assumed or observed so as to produce the opinion propounded (Makita at [85]; HG at [39]-[41]; see also Sydney Wide Distributors Pty Ltd v Red Bull Pty Ltd at [7]).

This, unfortunately, has tended to encourage only a perfunctory interest in the techniques and procedures relied upon by experts. In the case of expert identification evidence, most judges have been satisfied with a vague description of a procedure, even if the 'procedure' has not been shown to reliably produce the kinds of results claimed, and even if the 'procedure' merely involves macroscopic comparison of two images on a computer screen.

In addition, the exclusionary discretions, based on Christie at common law and ss 135 and 137 under the UEL, have exerted almost no discernible impact on the reception of opinion evidence about images. Intended to balance the probative value of evidence against the danger of unfair prejudice to the accused, they are rarely used to exclude incriminating expert opinion evidence adduced by the prosecution. Given the many weaknesses with facial mapping evidence we might expect that evidence of unknown probative value would be outweighed by the danger of unfair prejudice to the accused (at least some of the time). Judges, however, appear reluctant to make any assessment of the actual probative value of the prosecution's expert opinion evidence for fear of trespassing on the prerogatives of the jury (Edmond 2008b).

\section{Defence, Prosecution and the Adversarial Criminal Trial}

Judges tend to admit incriminating expert opinion evidence because they believe that problems with validity and reliability, like the credibility of an expert, can be productively explored during cross-examination, or by calling a rebuttal expert. This tendency does not acknowledge the very different roles that prosecution and defence experts play in criminal proceedings (and pleas). It is, moreover, not consistent with the traditional burden of proof. Whereas incriminating expert identification evidence typically forms part of the coherent circumstantial case against the accused, rebuttal evidence not infrequently involves discrete and sometimes technical criticisms of the expert opinion evidence adduced by the prosecutor. In consequence, it is not uncommon for rebuttal experts to report on problems and uncertainty without undertaking their own assessment or investigation. ${ }^{50}$

49 Even if the anatomists had been involved in anthropometrics and comparative anthropology in a way that might satisfy 'experience', judges and prosecutors should not disregard the validity and reliability of expert identification evidence.

50 Though, see the response in $R v$ Madigan at [107]. 
The admission of expert opinion evidence that is unreliable - or of unknown reliability places the defence at a serious disadvantage. Whenever the prosecution adduces expert identification evidence it obliges the defence to respond, either by cross-examining the expert witness (which typically requires expert assistance) or calling a rebuttal expert (if such an expert is available and affordable). Rather than require the prosecution to demonstrate the validity and reliability of their incriminating opinion evidence as a condition regulating admissibility, it transfers to the defence the responsibility for demonstrating that the evidence is unreliable or insufficiently certain. This represents inappropriate cost and burden shifting.

Furthermore, the conventional adversarial trial may be inadequate as a means of exposing the limitations with incriminating expert opinion evidence.

Just because cross-examination might be able to expose problems with a technique or an expert might be found who is willing to testify about weaknesses in the forensic science evidence, does not mean that these should provide the primary bulwark against unreliable and prejudicial expert opinion evidence adduced by the prosecution. Facilitating cross-examination or allowing the defence to call rebuttal expertise does not make a trial fair. Structural symmetry is not the same as substantial fairness (Edmond 2008b:38). ${ }^{51}$

\section{Directions and Warnings}

Frequently, as with other problematic forms of evidence, facial mapping is admitted upon the understanding that where robust adversarialism leaves residual risks, those risks can be reduced by judicial instruction. Unfortunately, almost all of the empirical research suggests that judicial comments, directions and warnings are either ineffective or of limited effectiveness (see ALRC 2005:591-595; Lieberman \& Sales 1999:18.1; Ogloff \& Rose 2005:407).

\section{Similarity/Difference Evidence}

It is important to acknowledge that senior judges have imposed some limitations on the provision of expert identification evidence derived from images. In NSW, for example, the CCA has endeavoured to prevent expert witnesses from making positive identifications (in court, at least). These limitations have been imposed in an attempt to reduce the potential for prejudice. Restricting facial mapping evidence to similarities, however, might not provide much in the way of meaningful protection to the accused. In most trials the jury is left with little doubt that it is the expert's considered opinion that there are no meaningful differences between the accused and the unknown person in the incriminating images.

Legal conventions, rather than scientific norms or empirical research, prevent experts from proffering their opinion and the strength of their conviction (Merton 1973:266-278; Mitroff 1974; Mulkay 1980). Ironically, these legal constraints, by imposing a veneer of caution and qualification, may make prosecution expert witnesses appear more rigorous and more credible than they actually are.

Allowing experts to provide evidence of similarities simply elides methodological scrutiny of whether anatomists, physical anthropologists and others, are actually able to see similarities and differences better than lay people, and, more fundamentally, whether any

51 In Murdoch, Jung, Alrekabi (2007) and Pera (2007 and 2008) trial judges and Courts of Criminal Appeal seem to have been comforted by the participation of experts called by the defence. 
similarities and differences in the images are real or artefactual. A formidable technical vocabulary and/or considerable experience dealing with bodies does not enable an anatomist to observe detail not captured in the recorded image, nor intuitively to overcome the distorting effects of lighting, shadows, angles, lenses or image perspective (e.g. Figures 3 and 6).

\section{Developing Negatives}

There are good reasons to doubt the probative value of expert identification evidence based on images as it currently appears in Australian (and English and New Zealand) courts. There are also good reasons to question many of the safeguards routinely invoked to reassure those concerned about the reliability of expert evidence, the fairness of trials and the safety of criminal convictions.

\section{Images as Evidence}

Since the inception of photography, scholars and practitioners have warned about using images to prove things. Photographs, they lament, are too often presumed to be neutral, mechanical facts-on-paper, whose close and careful scrutiny yields truth (Goodwin 1994, 1995). The proliferation and ubiquity of photographic and video images has given us a familiarity and confidence that creates a distorted sense of their reliability and accuracy. Long ago Walter Benjamin noted that technologies of image production and reproduction had the effect of 'democratising' visuality, but he simultaneously wondered, 'isn't a photographer who can't read his own pictures worth less than an illiterate?' (1935 [1980]:215). Today, this question is no longer rhetorical. In an age of mass surveillance, where cameras record many of our activities and interactions, those viewing the recorded images may be inclined to believe that an objective truth is readily available. ${ }^{52}$ Theorists suggest that we have become enculturated: 'reading' photographs as though we derive knowledge from them spontaneously or intuitively (Benjamin 1935 [1980]; Barthes 1981:6, 85; Sontag 1977:5, 153; 2002; Berger 1980:293; Bourdieu 1990:22; Eco 1982:32; Morris 1988:151; Solomon-Godeau 1991:189; Sekula 1984:96-97; Flusser 2000:52; Young 1996:16). John Tagg, an historian of photography, neatly captures this quandary: 'To serve as evidence and record, the image had to be said to speak for itself, though only qualified experts could read its lips' (1992:129; see also $R v$ Luttrell and Hamberger).

Despite admonitions and caveats, law has embraced photography's evidentiary prowess without ever developing an adequate jurisprudence. Jennifer Mnookin, in her legal history of photography, describes how in 1889, a Massachusetts lawyer argued that ' $[\mathrm{t}] \mathrm{he}$ photograph is something more than a copy; it is a fac simile, and it is a perfect record of facts, not subject to prejudice, bias, or defective memory' (1998:18). Nevertheless, early legal uses of photography (and x-rays) limited them to 'illustrating' other evidence, rather than serving as independent proof (Mnookin 1998:13, 43-44; Golan 2004b). This limitation rested upon an assumption that remains powerful today. Criminal courts have tended to prefer the evidence of eyewitnesses, particularly in the area of identification evidence. The UEL maintains this distinction; preferring identification evidence to come from

52 Compare Judith Butler's (1992) critique of the 'smart bomb' deployed in the first Gulf War, a bomb with a camera attached to it, that could not visually capture its own destructiveness. Butler wrote that the 'smart bomb' eliminated 'the phantasmatic distinction between the hit and its consequences' (at 11). 
identification parades. Identification based on photographs is deemed inferior and, in principle, only admissible when it is not 'reasonable' to conduct a live parade. ${ }^{53}$ The preference for eyewitness identification (whether live or from photographs) persists despite an expansive body of psychological scholarship documenting problems with eyewitness identification which, significantly for the criminal justice system, are accentuated by stress and pain, the presence of weapons and disguises, and racial differences. ${ }^{54}$ And, despite the fact that a high proportion of miscarriages of justice include mistaken eyewitness identification evidence (Scheck et al 2000). ${ }^{55}$

The High Court's decision in Smith created a market for expert identification evidence. It followed a trial where the eight eyewitnesses to a bank robbery gave conflicting descriptions of the particular offender, as: 'Aboriginal', 'coffee-colour', 'South American' and 'white'.56 Asking police officers to identify the robbers from security photographs was intended to overcome the problems with this inconsistent eyewitness evidence. ${ }^{57}$ The High Court decided that the evidence of the police officers added nothing to the jury's own capacity, particularly as the police officers had no 'expertise' that might help the jury to 'read' the photographs. When Smith was re-tried, without the police officers narrating the images, he was acquitted. $^{58}$

As the number of images associated with crimes has increased, identification 'experts' have entered the marketplace, purportedly free from the stresses and distractions that diminish the reliability of eyewitness and victim identifications. Unfortunately, little attention has been given to the reliability of their evidence, particularly the effect of 'race' remember Smith, BLM, Kaliyanda (Aboriginal defendants), Tang, Jung (Asian defendants), Pera (Fijian defendant) and Alrekabi (Iraqi defendant) - on the reliability of expert identification evidence as well as the impact of incriminating expert opinions in areas where lay people are known to experience difficulty.

\section{The Need for Demonstrable Reliability: Lewis (and Carroll)}

Despite the critical nature of this article, it is not our intention to reject all expert identification evidence based on images. While facial mapping evidence appears to be based upon untested techniques, loosely linked to experience and formal training, several techniques are currently being evaluated and refined and in some areas protocols have been proposed or could be. We will discuss the potential for expert identification based on images below. At this point, sensitive to the limitations with face and body mapping, we wish to emphasise the importance of making expert opinion evidence based on images more reliable and legal practice more responsive (Redmayne 2001; Roberts 2008). Our admissibility

53 UEL Pt 3.9. Influential cases like Alexander v The Queen have meant that judges now recognise some of the dangers with lay eyewitness identification evidence. Judges are expected to give a warning where identification evidence is in issue: s116.

54 The legal and psychological history of cross-racial identifications is outlined in New Jersey $v$ Cromedy, regarded in many US jurisdictions as persuasive authority. See also Johnson 1984, and the entire special theme issue of Psychology, Public Policy and Law (2001) titled 'The Other-Race Effect and Contemporary Criminal Justice: Eyewitness Identification and Jury Decision Making'.

55 Interestingly, Australian judges have been resistant to the use of psychologists to explain the limitations with eyewitness evidence, particularly in an attempt to de-bunk myths about lay identification evidence in stressful situations. See Smith v The Queen 1990; $R$ v Smith 2000; $R$ v Gassy (No 2).

56 Mundarra Smith v The Queen, S233/2000 and S234/2000 District Court transcript, extracted in High Court of Australia Appeal Book, 99-100, 104-105, 97, 103.

57 An early cinematic exploration of this theme is found in the Akira Kirosawa film Rashomon (1953).

58 For a more comprehensive critique of cross-racial identification, see Biber 2007:21- 26, 45-71. 
jurisprudence can assist this goal by insisting on reliability as a condition governing the admissibility of incriminating expert identification evidence. ${ }^{59}$

There is support for reading 'reliability' into 'specialised knowledge'. Even in Tang the judges placed a premium on 'knowledge'. They recognised that it 'connotes more than subjective belief or unsupported speculation'. Chief Justice Spigelman even accepted that the 'term applies to any body of known facts or to any body of ideas inferred from such facts on good grounds' (Tang at [153]-[154]). This definition was taken from Daubert $v$ Merrell Dow Pharmaceuticals, Inc (1993), a decision of the Supreme Court of the United States. In attempting to define Rule 702 of the Federal Rules of Evidence (1975) - which influenced the drafting of s79 of the UEL - the Supreme Court insisted on the need for evidentiary reliability when parsing the phrase 'scientific, technical or other specialized knowledge'. In so doing, the majority even presented a set of criteria that might be used to assist judges to gauge legal reliability. These criteria included whether the technique had been tested, published, peer reviewed, whether it was generally accepted as well as information about the rate of error. ${ }^{60}$ After Daubert, federal and most State courts in the United States require evidence of reliability as a basis for the admissibility of all expert evidence. $^{61}$

In 2000, the Federal Rules of Evidence were revised. Rule 702 now states:

If scientific, technical, or other specialized knowledge will assist the trier of fact to understand the evidence or to determine a fact in issue, a witness qualified as an expert by knowledge, skill, experience, training, or education, may testify thereto in the form of an opinion or otherwise, if (1) the testimony is based upon sufficient facts or data, (2) the testimony is the product of reliable principles and methods, and (3) the witness has applied the principles and methods reliably to the facts of the case.

Concern with reliability, self evidently, has become a central component of US admissibility jurisprudence.

More recently, the Canadian Supreme Court and several of the provincial courts of appeal have also placed increasing emphasis on the reliability of incriminating expert opinion evidence. Writing for the majority in $R v$ Trochym (2007) Deschamp J explained that in relation to expert opinion evidence, '[r]eliability is an essential component of admissibility'. She continued, 'evidence that is not sufficiently reliable is likely to undermine the fundamental fairness of the criminal process' (at [27]; see also $R v$ Mohan; $R$ $v D D ; R v J-L J ;$ Re Truscott).

Although reliability has never been a central concern of admissibility jurisprudence in Australia, it has featured prominently in a number of Australian appeals and inquiries, particularly those associated with notorious miscarriages of justice (Morling QC 1987 [Chamberlain Royal Commission]; Shannon QC 1984 [Splatt Royal Commission]; other references include Osland $v$ The Queen at [53]; HG v The Queen at [58]; Velevski $v$ The Queen at [82]). One of the clearest expressions emerged from the appeal in Lewis $v$ The

59 Here, at the risk of terminological confusion, we are reverting to the ordinary meaning of 'reliability' (i.e. trustworthiness) rather than the more technical meaning discussed earlier.

60 While, it is not our intention to suggest that the Daubert criteria are an accurate model of science or expertise, some of the criteria, like testing, the determination of error rates, along with publication and peer review would undoubtedly improve the quality of incriminating forensic science evidence. See Edmond 2008c.

61 The Daubert criteria were flexibly extended to all expert opinion evidence in Kumho Tire Co v Carmichael. 
Queen (1987). ${ }^{62}$ In Lewis, some of the odontologists engaged by the Crown to help secure the Chamberlain convictions compared a bite mark on the body of a complainant with the teeth of the accused and made a positive identification. Relevantly, these identification techniques were untested and of unknown reliability (Beecher-Monas 2009; see also Tomaszewski \& Girdwoyn 2006).

Criticising this evidence in the Court of Appeal of the Northern Territory, Justice Maurice insisted that it was incumbent upon the Crown 'to carefully lay the ground for the reception of the opinions expressed by [the odontologists]. It could only do this by proving the scientific reliability of the exercise they carried out' (Lewis $v$ The Queen at 122). Instead, the Crown 'chose to rely on the witness' qualifications and experience in the field of forensic dentistry generally, and, in particular, upon the impressive curriculum vitae' (at 122). Significantly, '[n]o experimental research was pointed to nor other studies which demonstrated the reliability of the deduction made by these witnesses' (at 122-123). For Maurice $\mathrm{J}$ it was 'not an answer ... to say the defence may draw it out in cross-examination; that is an abdication of the Crown's primary function in a criminal prosecution' (at 123-124; endorsed in $R v$ Tran at 242).

Authority, international trends, the parochial need for 'specialised knowledge', and the desire for fair trials should all encourage Australian judges to read 'reliability' into s79 of the UEL and the common law equivalents. It is our contention that, where incriminating expert identification evidence is involved, demonstrable reliability should be a prerequisite to admissibility. ${ }^{63}$ This would not only raise the quality of expert opinion evidence and reduce the number of false convictions, but simultaneously enhance the professionalism of our forensic science institutions and personnel. After all, formal qualifications, long experience and prior appearances in other courts are not credible substitutes for validation studies, error rates and proficiency testing. Nor should it be glibly assumed that procedural safeguards, exclusionary discretions and warnings afford adequate protection against incriminating expert identification evidence based on images.

\section{Codes of Conduct, Expert Guidelines and Professional Ethics}

The emphasis on reliability is important because court rules, codes of conduct and professional guidelines do not seem to offer a solution. They have not prevented - as we have endeavoured to explain - incriminating expert opinion evidence of unknown reliability from entering serious criminal proceedings. This is an important observation because it suggests that codes and ethical precepts may be little more than symbolic (or aspirational). ${ }^{64}$ In all of the Australian cases where an expert witness gave identification evidence based on images, the testimony was proffered in the shadow of quite elaborate codes of practice.

These codes make the expert witnesses' duty to the court unambiguous.

\section{General duty to the court}

(1) An expert witness has an overriding duty to assist the court impartially on matters relevant to the expert witness's area of expertise.

62 Lewis $v$ The Queen was handed down in the same year as the Morling Report (1987). See also $R v$ Carroll.

63 Consider the response to admissibility challenges to DNA evidence in $R v$ Karger and $R v$ Gallagher. In Gallagher at [36], [62], [72], [114], [140], for example, Barr J ruled that DNA typing was admissible under $\mathrm{s} 79$ on the basis that the system was properly validated, reliable and accurate.

64 For some discussion of impartiality and law reform, see Edmond 2005, 2009. 
(2) An expert witness's paramount duty is to the court and not to any party to the proceedings (including the person retaining the expert witness).

(3) An expert witness is not an advocate for a party. ${ }^{65}$

They also require an expert report (and implicitly testimony) to include:

(b) the facts, and assumptions of fact, on which the opinions in the report are based ...

(c) the expert's reasons for each opinion expressed,

(d) if applicable, that a particular issue falls outside the expert's field of expertise,

(e) any literature or other materials utilised in support of the opinions,

(f) any examinations, tests or other investigations on which the expert has relied, including details of the qualifications of the person who carried them out ...

(2) If an expert witness who prepares an expert's report believes that it may be incomplete or inaccurate without some qualification, the qualification must be stated in the report.

(3) If an expert witness considers that his or her opinion is not a concluded opinion because of insufficient research or insufficient data or for any other reason, this must be stated when the opinion is expressed. ${ }^{66}$

Notwithstanding these codes, expert witnesses called by the prosecution have not adverted to the lack of research or the need for testing, the unknown reliability of their opinions, the range of methodological problems with their opinions or precisely how their education, training and experience enables them to make the kinds of identifications and comparisons presented in reports and court. On the contrary, the absence of validation studies is often disguised by reference to publications, study and experience of marginal relevance. ${ }^{67}$ Sometimes experts contend that those working alongside them independently confirm - or peer review - their conclusions, even in the absence of validation studies or standardised procedures (consider Edmond 2008a).

Similarly, professional codes and formal ethical frameworks promoted by scientific institutions and forensic science societies, as well as those applying to prosecutors (and defence counsel), have not operated as effective barriers against the production and use of incriminating expert opinions of unknown reliability. ${ }^{68}$

65 Uniform Civil Procedure Rules 2005 (NSW) Sch 7, 2 and Practice Direction: Guidelines for Expert Witnesses in Proceedings in the Federal Court of Australia (2008). The expectations upon State employees and consultants could hardly be lower than the expectations imposed upon experts participating in civil litigation and its preparatory stages.

66 Uniform Civil Procedure Rules 2005 (NSW) Sch 7, 5(1), (2) and (3).

67 In Tang, at [72], the citations included law review articles and early papers but no studies that supported validity or reliability. Little, if any, of the critical work, which these witnesses must certainly have some awareness of, even if only from earlier court cases, seems to be included (or made explicit) in their reports.

68 ANZFSS, Code of Ethics <www.anzfss.org.au/code_of_ethics.htm> accessed 12 August 2008; NSWDPP, Code of Conduct (2008); OHCHR, Guidelines on the Role of Prosecutors (1990). 


\section{Improving Expert Identification Evidence Based on Images}

\section{Pragmatism Rather than Science: An Immediate (Intermediate) Step?}

Even in the absence of validation studies, dramatic improvement to the provision of expert identification evidence could be produced through the impositions of a simple prophylactic. Courts could, for example, require two different experts to each examine a single set of photographs - one would examine a reference set of images of the suspect, and the other a set of images of the unknown person associated with the crime - using a pre-determined set of anatomical parameters. Attention could even be focused on particular regions of the body or features, such as ears or nose or head shape, based on a preliminary examination of what the images of the unknown person appear to reveal. The descriptions prepared by each of the experts could then be compared. Differences between the descriptions would presumably lead to the exclusion of this evidence. Low level consistency might not be sufficiently probative to overcome the dangers (s137) or the expenditure of time and resources (s135). ${ }^{69}$

It is important to emphasise that such an approach is not a validation study. It would not overcome problems with similarity nor guarantee reliability. Rather, it represents a kind of pragmatism that reflects the need for more reliable expert identification evidence and provides an overly credulous judiciary with the means to prevent some of the most egregious expert identification evidence from gaining entry to criminal trials.

\section{Independent Validation and Reliability Studies}

Notwithstanding the previous paragraphs, to gain admissibility there should be evidence supporting the validity and reliability of incriminating expert opinion evidence. ${ }^{70}$ That is, there should be independent studies with positive results, published in peer-reviewed journals of international standing (or, at a minimum, made publicly available). Further, there should be judicial scrutiny of whether the techniques and theories used by the particular expert are sufficiently similar to those that have been validated as well as evidence of the particular expert's credentials and personal proficiency.

What would validation studies and proficiency testing look like? Any credible testing regime would require the candidates to make identifications or describe similarities and differences under controlled conditions. That is, where those testing the facial mapping 'experts' would have access to the identity of those in the images and the test subjects would not. The facial mappers would be given several sets of reference images and would be asked whether a person of interest in CCTV images resembled any of the persons in the reference photos, and why. They would be told that the persons of interest from the reference photos may not be included among the sample. Such tests could be readily operationalised.

\section{More Cautious Uses of Apparently Incriminating Images}

Earlier, in Tang, we encountered Dr Sutisno referring to 'unique identifiers'. While the features described by Dr Sutisno (e.g. 'wide and thick ... lips' and 'square chin') do not

${ }^{69}$ This would, of course, need to be a formal process. The two experts would need to be spatially removed and genuinely independent.

70 The prosecution must satisfy the trial judge, using evidence, that on the balance of probabilities, the techniques are reliable. See Beecher-Monas 2006. 
strike us as 'unique', it is important to acknowledge that there will be times when facial and body features appearing in images are not particularly controversial and could facilitate confident and possibly even positive identifications (or reliably contribute to a circumstantial case). A distinctive tattoo, for example, especially if combined with other discriminating features (e.g. skin blemishes or scars) and captured in clearly resolved images, would generally provide highly probative evidence. Similarly, there will be occasions where even a casual inspection of images - including poorly resolved images would allow a lay observer to distinguish an offender from a person of interest. Where the person of interest is missing an arm and the suspect has all four limbs affords a very simple example. Most cases will be far less clear. In many cases it will be preferable to allow images to go before the jury without the incriminating, though untested, opinions of 'experts' or to simply exclude poorly resolved images because they have low probative value and the dangers to the accused are considerable. ${ }^{71}$ Unless identification experts validate their practices they should not be allowed to interpret images in court regardless of whether the images are highly resolved, taken with the same cameras, at the same angles and with similar image perspectives. And, if images have limited potential for identification purposes then it may be unfairly prejudicial to the accused to show them to the jury, especially where they depict violence.

The main difficulty with the use of images is determining if and when they should be presented to the jury. That is, deciding whether the images are sufficiently clear, unambiguous or reliable to enable recourse to individuating (i.e. particularly distinctive) features, and in what circumstances the images are sufficiently clear to enable the exclusion of particular suspects (see Hauser 2004; US v Johnson; Bruegge 1999; consider also Ashcroft v Free Speech Coalition; US v Fabrizio; US v Salcido; US v Rodriguez-Pacheco). For, images can provide probative evidence but they can also mislead. Often they mislead in ways that are insidious, because they unwittingly deceive viewers: whether experts, lawyers, jurors or judges. We need to be careful about the circumstances in which we allow experts to narrate the contents of images, particularly where the narration makes them incriminating. In the absence of validation studies we should, perhaps, be more inclined to use images to exclude suspects rather than inculpate them. However, we also need to recognise that the unreliability of any interpretation can cut both ways. It would be wrong to think, in the absence of further research, that we could rely upon images for exoneration where considerable scope for interpretation remains. Differences, like apparent similarities, may be artefactual.

Obviously these issues raise jurisprudential complexities and require more informed exercise of judicial discretions. They reinforce the need for further empirical research and the elaboration of a range of standards pertaining to: clarity of the image; the range, size and duration of the feature(s) depicted; data storage; the use of enhancement capabilities; ways to handle angle and image perspective; and, the impact of background factors. ${ }^{72}$ Judges should mediate jury access to images in ways that are sensitive to actual limitations and dangers as well as the difficulty of repairing misleading impressions in the context of the accusatorial criminal trial. Admission simpliciter, like the opinions of experts and judicial

71 Admission always needs to be considered against the criticisms developed earlier as well as the need to determine the probative value and weigh it against any unfair prejudice: UEL ss 135, 137.

72 Porter is currently working on resolution standards that might help judges to make admissibility determinations. 
directions, will not always provide the most appropriate way of dealing with (apparently) incriminating images.

\section{Law's Looking Glass}

The treatment of expert identification evidence holds a mirror to our criminal justice system and its rationalistic pretensions. For the reasons we have outlined, unreliable incriminating expert opinion evidence and incriminating opinion evidence of unknown reliability should not be allowed to contaminate criminal trials. Although this article examined the epistemologically flimsy case of facial mapping, the fact that this opinion evidence has been admitted, relied upon and withstood appeals should induce disquiet. This disquiet will not be diminished by the knowledge that many of the problems with facial mapping are applicable to other types of forensic science evidence (e.g. voice identification, footprints, earprints, bite marks, tool marks, ballistics, blood spatter, hair comparison and fingerprints) (Saks \& Koehler 2005; Beecher-Monas 2006; Saks \& Faigman 2008; US National Research Council 2009).

\section{Cases}

\section{Australia}

Alexander v The Queen (1981) 145 CLR 395

ASIC v Rich (2005) 53 ACSR 623

Bropho v Western Australia [2007] WADC 77

Clark v Ryan (1960) 103 CLR 486

Commissioner for Government Transport v Adamcik (1961) 106 CLR 292

$H G v$ The Queen [1999] HCA 2; (1999) 197 CLR 414

In the matter of the appeal of BLM (unreported) NSWDC, 14 September 2005

Lewis $v$ The Queen (1987) 88 FLR 104

Makita (Australia) Pty Ltd v Sprowles [2001] NSWCA 305

Murdoch $v$ The Queen [2007] NTCCA 1

NAFC v Minister for Immigration and Multicultural and Indigenous Affairs [2003] FCAFC

22

Osland v The Queen (1998) 197 CLR 316

$R$ v Alrekabi [2007] NSWDC 110

$R v$ Bonython (1984) 38 SASR 45

$R v$ Carroll (1985) 19 A Crim R 410

$R v$ Dann [2000] NSWCCA 185

$R v$ Gallagher [2001] NSWSC 462

$R v$ Gassy (No 2) [2005] SASC 491

$R v$ Tang [2006] NSWCCA 167

$R v$ Jung [2006] NSWSC 658

$R v$ Kaliyanda (unreported interlocutory judgment) NSWSC, 17 October 2006 
$R v$ Karger [2001] SASC 64

$R v$ Leung and Wong [1999] NSWCCA 287

$R v \operatorname{Li}$ [2003] NSWCCA 290

$R v$ Madigan [2005] NSWCCA 170

$R v$ Marsh [2005] NSWCCA 331

$R v$ Murdoch [2005] NTSC 78

$R v$ Pantoja (1996) 88 A Crim R 554

$R v$ Pera (2006/00014446 District Court of NSW)

$R v$ Smith [1999] NSWCCA 317; (1999) 47 NSWLR 419

$R v$ Smith [2000] NSWCCA 388

$R v$ Tang [2006] NSWCCA 167

$R v$ Tran (1990) 50 A Crim R 233

Ramsay $v$ Watson (1961) 108 CLR 642

SHJB v Minister for Immigration and Multicultural and Indigenous Affairs [2003] FCA 502

Smith v The Queen (1990) 64 ALJR 588

Smith v The Queen [2001] HCA 50; (2001) 206 CLR 650

Sydney Wide Distributors Pty Ltd v Red Bull Pty Ltd [2002] FCAFC 157

Velevski v The Queen [2002] HCA 4; (2002) 187 ALR 233

\section{Canada}

$R v D D[2000] 2$ SCR 275

$R v J-L J[2000] 2$ SCR 600

$R v$ Mohan [1994] 2 SCR 9

$R v$ Trochym [2007] 1 SCR 239

Re Truscott [2007] ONCA 575

\section{United Kingdom}

Attorney General's Reference (No 2 of 2002) [2002] EWCA Crim 2373

Davie v Edinburgh Magistrates [1953] SC 34

$R v$ Christie [1914] AC 545

$R v$ Clarke [1995] 2 Cr App R 425

$R v$ Doheny and Adams [1997] 1 Cr App R 369

$R v$ Gray [2003] EWCA Crim 1001

$R v$ Hoey [2007] NICC 49

$R v$ Hookway [1999] EWCA Crim 212

$R v$ Luttrell and Hamberger [2004] EWCA Crim 1344

$R v$ Robb (1991) 93 Cr App R 161

$R v$ Stockwell (1993) 97 Cr App R 260

\section{United States}

Ashcroft v Free Speech Coalition 535 US 234 (2002)

Daubert v Merrell Dow Pharmaceuticals, Inc 509 US 579 (1993)

General Electric Co v Joiner 522 US 136 (1997) 
Kumho Tire Co v Carmichael 526 US 137 (1999)

New Jersey $v$ Cromedy 158 NJ 112 (1999)

People v Collins 438 P 2d 33 (68 Cal 2d 319 1968)

US v Fabrizio 445 F Supp 2d 152 (2006)

US v Fabrizio 463 F Supp 2d 111 (2006)

US v Johnson 114 F 3d 808 (1997)

US v Rodriguez-Pacheco $475 \mathrm{~F} 3 \mathrm{~d} 434$ (2007)

US v Salcido 506 F 3d 729 (2007)

\section{References}

Allison H 1973 Personal Identification Holbrook Press Boston

Australian Law Reform Commission 2005 Uniform Evidence Law: Report 102 Southwood Press Sydney

ANZFSS Code of Ethics <www.anzfss.org.au/code of ethics.htm> accessed 12 August 2008

Aronson J 2007 Genetic Witness: Science, Law, and Controversy in the Making of DNA Profiling Rutgers University Press New Brunswick

Association of Chief Police Officers of England, Wales and Northern Ireland 2003 National Working Practices in Facial Imaging $<$ www.acpo.police.uk/asp/policies/Data/garvin facial_imaging_guidelines.doc $>$ accessed 12 March 2009

Baden M \& Roach M 2002 Dead Reckoning: The New Science of Catching Killers Simon \& Schuster New York

Barthes R 1981 Camera Lucida Hill and Wang New York

Beavan C 2002 Fingerprints: Murder and the Race to Uncover the Science of Identity Fourth Estate London

Beecher-Monas E 2006 Evaluating Scientific Evidence Cambridge University Press Cambridge

Beecher-Monas E 2009 'Reality bites' Cardozo Law Review vol 30 (forthcoming)

Benjamin W (1968) 'The work of art in the age of mechanical reproduction' in Benjamin W Illuminations Schocken New Yorkpp 199-216

Berger J 1980 'Understanding a photograph' in Trachtenberg A (ed) Classic Essays on Photography University of Chicago Press Chicago pp 290-299

Biber K 2002 'The hooded bandit: Aboriginality, photography and criminality in Smith v The Queen' Current Issues in Criminal Justice vol 13 pp 286-300

Biber K 2006 'The Spectre of Crime: Photography, Law and Ethics' Social Semiotics vol 16 pp 133-149 
Biber K 2007 Captive Images: Race, Crime, Photography Routledge-Cavendish London

Bodziak W 2000 Footwear Impression Evidence: Detection, Recovery and Examination 2nd edn CRC Press Boca Raton FL

Bourdieu P 1990 Photography: A Middle-Brow Art Polity Press Cambridge

Bromby M 2003 'At face value?' New Law Journal Expert Witness Supplement vol 153 pp 302-304

Bruegge V 1999 'Photographic identification of denim trousers from bank surveillance film' Journal of Forensic Sciences vol 44 pp 613-622

Burton M, Wilson S, Cowan M, Bruce V 1999 'Face recognition in poor-quality video: Evidence from security surveillance’ Psychological Science vol 10 pp 243-248

Butler J 1992 'Contingent foundations: Feminism and the question of "post-modernism"' in Butler J \& Scott J (eds) Feminists Theorise the Political Routledge New York pp 3-21

Campbell-Tiech A 2005 “'Stockwell” revisited: The unhappy state of facial mapping' Archbold News vol 6 pp 4-6

Cohen N, Gattuso J \& MacLennan-Brown K 2007 'CCTV Operational Requirements Manual: Is your CCTV system fit for the purpose?' 55/06 Version 4, Home Office Scientific Development Branch

Cole S 2001 Suspect Identities: A History of Fingerprinting and Criminal Identification Harvard University Press Cambridge MA

Cole S 2004 'Grandfathering evidence: Fingerprint admissibility rulings from Jennings to Llera Plaza and back again’ American Criminal Law Review vol 41 pp 1189-1276

Cole S 2006 'Is fingerprinting valid? Rhetorics of reliability in fingerprint proponents' discourse' Law and Policy vol 28 pp 109-135

Costigan R 2007 'Identification from CCTV: the risk of injustice' Criminal Law Review pp 591-608

Dror I \& Rosenthal R 2008 'Meta-analytically quantifying the reliability and bias ability of forensic experts' Journal of Forensic Sciences vol 53 pp 900-903

Dror I, Charlton D \& Peron A 2006 'Contextual information renders experts vulnerable to making erroneous identifications’ Forensic Science International vol 156 pp 74-78

Eco U 1982 'Critique of the image' in Burgin V (ed), Thinking Photography Macmillan London pp 32-39

Edmond G 2005 'Judging Surveys: Experts, empirical evidence and law reform' Federal Law Review vol 33 pp 95-139

Edmond G 2008a 'Judging the scientific and medical literature: Some legal implications of changes to biomedical research and publication' Oxford Journal of Legal Studies vol 28 pp 523-561 
Edmond G 2008b 'Specialised knowledge, the exclusionary discretions and reliability: Reassessing incriminating expert opinion evidence' University of New South Wales Law Journal vol 31 pp 1-55

Edmond G 2008c 'Pathological science: Demonstrable Reliability and Expert Forensic Pathology Evidence' in Roach K (ed) Pediatric Forensic Pathology and the Justice System Ontario Ministry of the Attorney General Toronto pp 91-149Edmond G 2009 'Merton and the hot tub: Scientific conventions and expert evidence in Australian civil procedure' Law and Contemporary Problems vol 72 (forthcoming)

Edmond G \& San Roque M 2009 'Quasi-justice: Ad hoc expertise and identification evidence’ Criminal Law Journal vol 33 pp 8-33

Flusser V 2000 Towards a Philosophy of Photography Reaktion Books London

Galton F 1883 Inquiries into the Human Faculty and its Development JM Dent \& Co London

Gans J 2007a 'The Peter Falconio Investigation: Needles, Hay and DNA' Current Issues in Criminal Justice vol 18 pp 415-430

Gans J 2007b 'Catching Bradley Murdoch: Tweezers, Pitchforks and the limits of DNA sampling' Current Issues in Criminal Justice vol 19 pp 34-48

Golan T 2004a Laws of Men and Laws of Nature Harvard University Press Cambridge MA

Golan T 2004b 'The Emergence of the Silent Witness: The Legal and Medical Reception of X-rays in the USA' Social Studies of Science vol 34 pp 469-499

Good A 2006 Anthropology and Expertise in the Asylum Courts Routledge-Cavendish London

Goodwin C 1994 ‘Professional Vision’ American Anthropologist vol 96 pp 606-633

Goodwin C 1995 'Seeing in Depth’ Social Studies of Science vol 25 pp 237-274

Goudge S 2008 Inquiry into Pediatric Forensic Pathology in Ontario Volume 1 Ontario Ministry of the Attorney General Toronto

Hauser K 2004 'A Garment in the Dock; or, How the FBI Illuminated the Prehistory of A Pair of Denim Jeans' Journal of Material Culture vol 9 pp 293-313

Horswell J (ed) 2004 The Practice of Crime Scene Investigation CRC Press Boca Raton FL

Hutchings P 2001 The Criminal Spectre in Law, Literature and Aesthetics: Incriminating Subjects Routledge London

Johnson SL 1984 'Cross-Racial Identification Errors in Criminal Cases' Cornell Law Review vol 69 pp 934-987

Kemp R, Towell N \& Pike G 1997 'When seeing should not be believing: Photographs, credit cards and fraud' Applied Cognitive Psychology vol 11 pp 211-222

Kemp R \& Coulson K 2008a 'Facial mapping and forensic photographic comparison" An international survey' (in preparation) 
Kemp R, Heidecker S \& Johnston N2008b 'Identification of suspects from video: Facial mapping experts and the impact of their evidence' paper presented at the 18th Conference of the European Association of Psychology and Law, Maastricht, 2-5 July 2008

Lieberman J \& Sales B 1999 'The effectiveness of jury instructions' in Abbott W \& Batt J (eds) A Handbook of Jury Research American Law Institute Philadelphia 18.1-18.73

Loftus EF 1976 'Unconscious transference in eyewitness identification' Law and Psychology Review vol 2 pp 93-98

Lynch M 2004 'Science above all else' in Edmond G (ed) Expertise in Regulation and Law Ashgate Aldershot pp 121-135

Lynnerup N, Andersen M \& Lauritsen HP 2003 'Facial image identification using Photomodeler ${ }^{\circledR}$ ' Legal Medicine vol 5 pp 156-160

Mardia K, Coombes A, Kirkbride J, Lynely A \& Bowie JL 1996 'On statistical problems with face identification from photographs' Journal of Applied Statistics vol 23 pp 655675

Marr D 2003 Dark Victory Allen \& Unwin Sydney

Merton R 1973 The Sociology of Science: Theoretical and Empirical Investigations University of Chicago Press Chicago

Mitroff I 1974 The Subjective Side of Science Elsevier New York

Mnookin J 1998 'The image of truth: Photographic evidence and the power of analogy' Yale Journal of Law and the Humanities vol $10 \mathrm{pp}$ 1-74

Morling QC, T 1987 Royal Commission into the Conviction of Lindy and Michael Chamberlain Government Printer Canberra

Morris M 1988 'On the "On" of On Photography' in The Pirate's Fiancee: Feminist, Reading, Postmodernism Verso New York pp 151-159

Mulkay M 1980 'Interpretation and the use of rules: the case of the norms of science' in Gieryn T (ed) Science and Social Structure New York Academy of Sciences New York pp 111-125

NSWDPP 2008 Code of Conduct $<$ http://www.odpp.nsw.gov.au/publications/Code $\% 20$ of $\%$ 20conduct.pdf $>$ accessed 12 March 2009

Ogloff J \& Rose G 2005 'The comprehension of judicial instructions' in Brewer N \& Williams K (eds) Psychology and Law: An Empirical Perspective p 407

OHCHR 1990 Guidelines on the Role of Prosecutors < http://www2.ohchr.org/english/law/ prosecutors.htm> accessed 12 March 2009

Porter G \& Doran G 2000 'An anatomical and photographic technique for forensic facial identification’ Forensic Facial Identification vol 114 pp 97-105

Porter G 2007 'Visual Culture in Forensic Science' Australian Journal of Forensic Sciences vol 39 pp 81-91 
Porter G 2008 'CCTV Images as Evidence' Plenary lecture Australian Academy of Forensic Sciences 28 May

Psychology, Public Policy and Law 2001 vol 7 Special Issue 'The Other-Race Effect and Contemporary Criminal Justice: Eyewitness Identification and Jury Decision Making’

Purkait R \& Singh P 2008 'A test of individuality of human external ear pattern: Its application in the field of personal identification' Forensic Science International vol 178 pp 112-118

Redmayne M 2001 Expert Evidence and Criminal Justice Oxford University Press Oxford

Roberts A 2008 'Drawing on expertise: legal decision making and the reception of expert evidence' Criminal Law Review pp 443-462

Saks M \& Koehler J 2005 'The coming paradigm shift in forensic identification science' Science vol 309 pp 892-895

Saks M \& Faigman D 2008 'Failed forensics: How forensic science lost its way and how it might yet find it' Annual Review of Law and Social Science vol 4 pp 149-171

Scheck B, Neufield P \& Dwyer J 2000 Actual Innocence Double Day New York

Sekula A 1984 Photography Against the Grain Nova Scotia University Press Halifax

Shannon QC, C 1984 Royal Commission Report Concerning the Conviction of Edward Charles Splatt Government Printer South Australia Adelaide

Solomon-Godeau A 1991 Photography at the Dock: Essays on Photographic History, Institutions and Practices University of Minneapolis Press Minneapolis

Sontag S 1977 On Photography Farrar, Straus \& Giroux New York

Sontag S 2002 'Looking at War' New Yorker 9 December

Stanislaw H \& Todorov N 1999 'Calculation of signal detection theory measures' Behavior Research Methods, Instruments and Computers vol 31 pp 137-149

Tagg J 1988 The Burden of Representation Macmillan Basingstoke

Tagg J 1992 Grounds of Dispute Macmillan Basingstoke

Tomaszewski T \& Girdwoyn P 2006 'Scent identification evidence in jurisdiction' Forensic Science International vol 162 pp 191-195

Tribe L 1971 'Trial by mathematics’ Harvard Law Review vol 84 pp 1329-1393

US National Research Council 1996 The Evaluation of Forensic DNA Evidence National Academy Press Washington DC

US National Research Council 2009 Strengthening Forensic Science in the United States: A Path Forward National Academy Press Washington DC

Valverde M 2006 Representing Law and Order Routledge-Cavendish London

Young A 1996 Imagining Crime Sage London

Young A 2005 Judging the Image: Art, Value, Law Routledge London 